\title{
$C_{0} \mathbf{I} \cdot \mathbf{R}^{\circ} \mathbf{P} \cdot \mathrm{E}^{\prime} \mathrm{E}$
}

Centre Interuniversitaire sur le Risque, les Politiques Économiques et l'Emploi

Cahier de recherche/Working Paper 12-15

\section{Entry, Imperfect Competition, and Futures Market for the Input}

Georges Dionne

Marc Santugini

Mars/March 2012

Version révisée Juin/June 2014

Dionne: Department of Finance, CIRPÉE and CIRRELT, HEC Montréal, Canada georges.dionne@hec.ca

Santugini: Institute of Applied Economics and CIRPÉE, HEC Montréal, Canada

marc.santugini@hec.ca

We thank an associate editor and two anonymous referees for their very helpful comments. We also thank Catherine

Gendron-Saulnier for excellent research assistance. Finally, we thank Claude-Denys Fluet, Anabelle Maher, Nicolas Papageorgiou, Michel Poitevin, as well as seminar participants at HEC Montréal, Les Journées du CIRPÉE 2011, and the 2012 Canadian Economics Association Annual Conference for their comments. 


\begin{abstract}
:
We analyze firms' entry, production and hedging decisions under imperfect competition. We consider an oligopoly industry producing a homogeneous output in which risk-averse firms face an entry cost upon entering the industry, and then compete in Cournot with one another. Each firm faces uncertainty in the input cost when making production decision, and has access to the futures market to hedge the random cost. We provide two sets of results. First, under general assumptions about risk preferences, demand, and uncertainty, we characterize the unique equilibrium. In contrast to previous results in the literature (without entry), production and output price depend on uncertainty and risk aversion. Specifically, when entry is endogenized and the futures price is not actuarially fair, access to the futures market does not lead to separation. Second, to study the effect of access to the futures market on entry and production, we restrict attention to constant absolute risk aversion (CARA) preferences, a linear demand, and a normal distribution for the spot price. In general, the effect of access to the futures market on the number of firms and production is ambiguous.
\end{abstract}

Keywords: Cournot, Entry, Futures, Hedging, Imperfect Competition

JEL Classification: D21, D43, D80, G32, L13 


\section{Introduction}

Recent financial literature on firms' risk management of market risk has focused on the determinants of hedging and the economic value of financial coverage. The two main questions in this literature are: Why do firms hedge? and Does hedging increase the economic value of the firms? Firms' hedging is explained by managerial risk aversion (Stulz, 1990; Tufano, 1996) or market imperfections such as corporate income taxation (Smith and Stulz, 1985; Graham and Smith, 1999; Graham and Rogers, 2002), financial distress costs (Smith and Stulz, 1985), corporate governance (Dionne and Triki, 2013), investment opportunity costs (Froot et al., 1993; Froot and Stein, 1998), and information asymmetries (DeMarzo and Duffie, 1991). The empirical effect of hedging on firm value is rather mixed (Hoyt and Liebenberg, 2011; Campello et al., 2011).

Another strand of the literature analyzes the joint production and hedging decisions of the firm under uncertainty about output price (Holthausen, 1979; Feder et al., 1980). The main result from this literature is that optimal output production is independent of the probability distribution of the output price and the manager's risk aversion. The distribution of the output price and risk aversion have an effect only on firms' involvement in futures trading. Hence, with access to the futures market, uncertainty does not introduce any efficiency loss in production. The same separation result is obtained under perfect competition and input price uncertainty (Holthausen, 1979; Katz and Paroush, 1979; Paroush and Wolf, 1992). Paroush and Wolf (1992) show, however, that the separation result does not hold in the presence of basis risk, while Anderson and Danthine (1981) obtain a similar negative result with production uncertainty. Different extensions have been proposed by considering multiple risky inputs, background risk, and joint output price and input price uncertainty. ${ }^{1}$

Although there are many contributions regarding firms' hedging in both literatures, to our knowledge there are few analyses of firms' hedging behav-

\footnotetext{
${ }^{1}$ See Viaene and Zilcha (1998) for instance. See also Alghalith (2008) for a review of the literature with competitive markets.
} 
ior under imperfect competition, and none that considers entry in the output market. $^{2}$ We propose to fill the gap by analyzing firms' entry, production and hedging decisions under imperfect competition. Specifically, we consider an oligopoly industry producing a homogeneous output in which risk-averse firms face an entry cost upon entering the output industry, and, then, compete in Cournot with one another. ${ }^{3}$ Each firm faces uncertainty in the input cost when choosing production, and has access to the futures market to hedge the random cost. There is only one source of risk in our analysis. ${ }^{4}$ One application of our model is the airline market for which it has been verified in empirical investigations of the U.S. airline industry that Cournot competition is present (Brander and Zhang, 1990; Fisher and Kamerschen, 2003). In this market, airline companies face future fuel price uncertainty when they make their optimal routes decisions for the next few months, and purchase futures contracts for jet fuel (Morrell and Swan, 2006). ${ }^{5}$ Here, entering or exiting the output market is mainly interpreted as route decisions.

We provide two sets of results. First, under general assumptions about

\footnotetext{
${ }^{2}$ There are three notable exceptions for imperfect competition. First, Eldor and Zilcha (1990) study the hedging behavior of an oligopoly under uncertainty in the output sector. However, while the spot price is endogenous (and the firms exercise market power under uncertainty), the futures (or forward) price is exogenous and fixed. In other words, the firms exercise market power in the spot output market, but behave perfectly competitively for the futures market of the same good. In addition, Eldor and Zilcha (1990) do not consider entry, which is our main focus in this paper. Second, in a very different setting, Allaz and Villa (1993) isolate the strategic reasons for using futures contracts. By selling futures contracts, Cournot firms attach a lower value to a high spot price and commit to aggressive behavior on the spot price yielding more production at a lower price in equilibrium, which benefits consumers but not producers. Third, the effect of strategic hedging on Cournot and Bertrand competition is studied in Léautier and Rochet (2012). We compare Léautier and Rochet (2012) model with our model and results later in the introduction.

${ }^{3}$ In this study, we assume that the firms have a concave payoff due to managerial risk aversion. Concavity can be explained by different market imperfections. See Froot et al. (1993) for a discussion.

${ }^{4}$ For the case of two types of risk (e.g., a risk that can be hedged through a financial derivative and a risk that can be insured by an insurance contract), see Rochet and Villeneuve (2011).

${ }^{5}$ Fuel cost represents about $15 \%$ of the airlines' costs. Other costs are usually less volatile so hedging fuel costs guarantees stable profits. Usually, airlines do not hedge business cycle risk. Airline companies can also purchase other derivatives products such as options and even collars. These options would introduce more flexibility for the firm at a higher cost, but would not affect the main results of the paper.
} 
risk preferences, demand, and uncertainty, we show that there exists a unique equilibrium in which a finite number of firms enter the market as long as the entry cost is not too high (the standard case) or not too low. Indeed, if the cost of entry in the output industry is too low, an infinite number of firms may enter the output industry and engage in speculation in the futures market, which yields the competitive outcome in the real sector. That is, the price of the output is equal to the marginal cost and the firms only make profits from speculating on the input market. We also show that, in contrast to previous results in the literature, production and output price depend on uncertainty and risk preferences. In particular, production and output price depend on the distribution of the spot price and risk aversion. The key element is that the entry decision coupled with a non-actuarially fair futures price limits the ability of the firms to adjust their production decisions, which implies that output is no longer independent of uncertainty and risk aversion. One implication is that access to the futures market alters the comparative analysis. If there is no access to the futures market, either a mean-preserving increase in risk or an increase in risk aversion induces each firm to produce less. If there is access to the futures market, such changes imply an increase (rather than a decrease) in per-firm production. ${ }^{6}$

The second set of results concern the effect of access to the futures market on entry, production, and prices. To study this effect, we restrict attention to constant absolute risk aversion (CARA) preferences, a linear demand, and a normal distribution for the spot input price. The effect of access to the futures market on the number of firms is ambiguous depending on the value of the futures price and the parameters of the model. Further, the equilibrium number of firms is convex in the futures price when the firms partially hedge. In particular, an increase in the futures price of the input can yield an increase in the number of firms in the output sector. This is due to the fact that an increase in the futures price induces firms to produce less, which reduces the market externality in a Cournot game and induces

\footnotetext{
${ }^{6}$ The result without financial access is consistent with classical results obtained in a static environment (i.e., without entry decision) for perfect competition (Sandmo, 1971; Batra and Ullah, 1974) and quantity-setting monopoly (Leland, 1972).
} 
more firms to enter while hedging their cost. Moreover, hedging induces each risk-averse firm to produce more.

As noted, very few articles study the interaction of real and financial activities when the firms exert market power. One exception is a recent paper by Léautier and Rochet (2012) which studies the effect of committing to a hedging strategy on production or pricing strategies. Specifically, Léautier and Rochet (2012) considers a two-stage game in which each firm commits to a hedging strategy in the first stage and then chooses production or pricing strategies in the second stage. As in our model, the firms have market power in the output sector but are perfectly competitive in the input market. There are however main differences in the setups as well as in the issues studied. Regarding the model, Léautier and Rochet (2012) considers a market with a fixed number of firms, each one committing to a hedging strategy before production or pricing strategies. In our model, entry is a decision variable in the first stage whereas hedging and production are chosen simultaneously in the second stage.

Beyond the differences in modeling, we study different and complementary aspects of the link between real and financial activities when the firms exert market power. Léautier and Rochet (2012) shows that strategic hedging (when used as a strategic commitment device) has a profound effect on the real decisions of the firms. Specifically, under actuarially fair pricing, when the firm commits to a hedging strategy, hedging toughens quantity competition, but softens price competition. We also consider issues related to risk management and real activities but of different nature. Specifically, we show that the separation result does not hold in the long-run when market structure is endogenized and the futures price is not actuarially fair. ${ }^{7}$ We then study the effect of access to the futures market on entry and production decisions. $^{8}$

\footnotetext{
${ }^{7}$ As noted, separation means that production decisions are independent of uncertainty and risk preferences, and depend only on the futures price (Danthine, 1973; Holthausen, 1979; Feder et al., 1980).

${ }^{8}$ In other words, we show how commitment in entry removes the separation result obtained in the literature (i.e., production strategies depend on uncertainty and risk preferences in the long run) whereas Léautier and Rochet (2012) shows that commitment in hedging has a profound effect on Bertrand or Cournot competition.
} 
The paper is organized as follows. Section 2 presents the model and defines the equilibrium. Section 3 states the equilibrium and presents results related to the issue of separation. Section 4 discusses the effect of access to futures market on entry. Section 5 concludes the paper. Main proofs are found in the Appendix of this paper whereas the remaining proofs and extensions are found in the online Appendix provided by Dionne and Santugini (2014).

\section{Model}

In this section, we present the model and define the free-entry equilibrium with access to the futures market. In the next sections, we analyze the equilibrium. Under a general characterization of the unique equilibrium, we show that the entry decision links production and output price to uncertainty and risk aversion.

\section{$2.1 \quad$ Preliminaries}

We embed access to the futures market in a two-stage entry game. At the first stage, all potential firms decide whether to enter an industry in the output sector. Each entering firm faces an exogenous entry cost. ${ }^{9}$ At the second stage, all firms that have entered make production and financial decisions while competing in Cournot in the output sector. The firms face uncertainty in the input price, but have access to perfectly competitive spot and futures markets. Figure 1 describes the timeline of the model. ${ }^{10}$

We now describe the second stage of the game. In an industry with $J$ firms, firm $j$ produces $q_{j} \geq 0$ units of output and faces the inverse demand $p=P\left(\sum_{k=1}^{J} q_{k}\right)$ where $p$ is the output price and $q_{k}$ is the output sold by firm

\footnotetext{
${ }^{9}$ The case of no entry cost is excluded. In the data, industries with access to and participation in the futures market generally comprise a small number of large firms. See Campello et al. (2011). It is well documented in the literature that large firms hedge (Stulz, 1996).

${ }^{10} \mathrm{We}$ abstract from bankruptcy or solvency problems that could arise after the spot input price is realized. Because we use futures contracts, there is no credit risk in the financial market.
} 


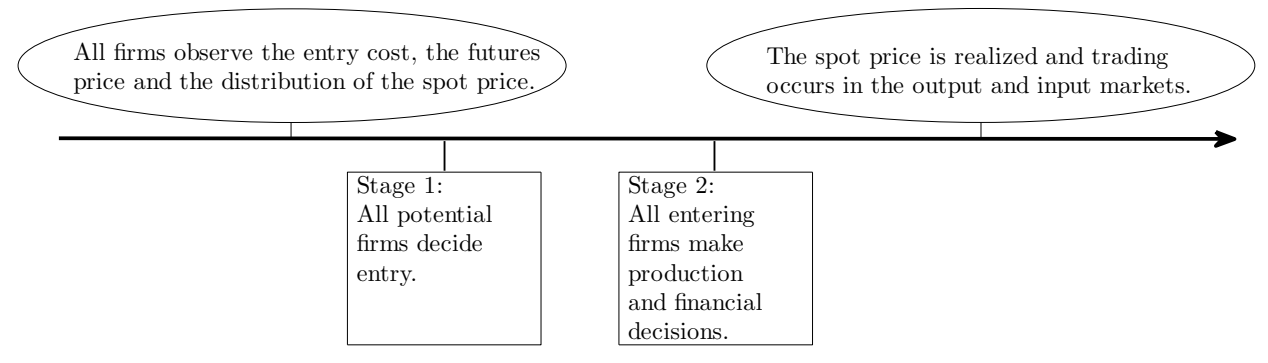

Figure 1: Timeline

$k$. The technology to transform the input into the output is assumed to be linear and deterministic. A unit of input can be purchased in the spot market at price $\tilde{S}$, which is unknown at the time of setting output. ${ }^{11}$ In addition to the spot market, there is a futures market for the input. A futures contract can be purchased at known price $F$ for delivery of one unit of input.

The decisions of the firm can be summarized by two variables: one related to production and another one related to financial activity. Specifically, firm $j$ sets output $q_{j} \geq 0$ and chooses the hedge coverage $\omega_{j} \in \mathbb{R}$ for the random cost so that firm $j$ purchases $\left(1-\omega_{j}\right) q_{j}$ units of input in the spot market at the random spot input price $\tilde{S}$, and buys futures contracts at the futures price $F$ for the remaining $\omega_{j} q_{j}$ units of input. ${ }^{12}$ Given production and financial decisions, the random profit of firm $j$ when there are $J$ firms in the industry is

$$
\pi\left(J, q_{j}, \omega_{j}, \sum_{k \neq j}^{J} q_{k}, \tilde{S}, F\right)=P\left(q_{j}+\sum_{k \neq j}^{J} q_{k}\right) q_{j}-\tilde{S}\left(1-\omega_{j}\right) q_{j}-F \omega_{j} q_{j}
$$

where the firms compete in Cournot in the output market, but are pricetakers in the (spot and futures) input markets. ${ }^{13}$

\footnotetext{
${ }^{11} \mathrm{~A}$ tilde sign distinguishes a random variable from a realization.

${ }^{12}$ In other words, firm $j$ purchases $x_{j} \equiv\left(1-\omega_{j}\right) q_{j}$ units of input in the spot market, and the remaining $y_{j} \equiv \omega_{j} q_{j}$ units are purchased in the futures market. Hence, $q_{j}=x_{j}+y_{j}$ units of output are produced.

${ }^{13}$ This situation is representative of industries that participate in the futures input markets. For instance, while airline companies have market power in providing their services, they cannot have an effect on the financial prices of the futures contracts for fuel
} 
Firms may engage in various types of financial activities. Specifically, firm $j$ may decide not to access the futures market, i.e., $\omega_{j}=0$. It may also partially hedge $\left(\omega_{j} \in(0,1)\right)$ or fully hedge $\left(\omega_{j}=1\right) .{ }^{14}$ It may finally engage in two forms of speculation, i.e., buying or selling futures contracts to generate pure financial profits without any link to profits derived from real production. First, when $\omega_{j}<0$, firm $j$ sells futures contracts at price $F$ which are deliverable by purchasing the input in the spot market. ${ }^{15}$ Second, when $\omega_{j}>1$, firm $j$ fully hedges, and buys additional units of input in the futures market for resale in the spot market. ${ }^{16}$ While firms whose main activity is production rarely speculate (e.g., the board often prevents the firm's managing team from speculating), it occurs and has occurred (Stulz, 1996). For our analysis, it turns out that allowing firms to engage in speculation simplifies the characterization of the equilibrium (i.e., no corner solution), and, more importantly, has no effect on most of our results. ${ }^{17}$

Note that the literature linking real decisions with access to futures markets uses the term speculation in two distinct ways. In Holthausen (1979) and Feder et al. (1980), $\omega_{j} \in(0,1)$ is interpreted as partial hedging or hedging less than the entire quantity, whereas the firm speculates when $\omega_{j} \notin[0,1]$. However, in Anderson and Danthine (1983), a different interpretation is offered. Specifically, $\omega_{j} \in(0,1)$ is interpreted as speculation. ${ }^{18}$ To understand

because many other industries interact in these futures market.

${ }^{14}$ Full hedging means that the input is purchased only in the futures market, whereas, under partial hedging, the input is purchased in both the spot and the futures markets.

${ }^{15}$ Consistent with Footnote $12, \omega_{j}<0$ implies that $x_{j}>0, y_{j}<0$, so that production is $q_{j}=x_{j}+y_{j}<x_{j}$ because some of the input purchased in the spot market is used for delivery via the futures market whereas the remaining input is used for production.

${ }^{16}$ Consistent with Footnote 12, $\omega_{j}>1$ implies that $x_{j}<0, y_{j}>0$.

${ }^{17}$ Assuming CARA preferences, a linear demand, and a normally distributed spot price, online Appendix 5 provides a full characterization of the equilibrium when the firms have restricted access to the futures market, i.e., the firms may hedge but cannot speculate.

${ }^{18}$ On pp. $375-376$ of Anderson and Danthine (1983) (in the case of farmers selling output on spot and futures markets), it is written farmers hedge the totality of their output prior to readjusting their position, as speculators, on the basis of the expected futures-cash price differential. 
the Anderson and Danthine (1983) interpretation, (1) is rewritten as

$\pi\left(J, q_{j}, \omega_{j}, \sum_{k \neq j}^{J} q_{k}, \tilde{S}, F\right)=P\left(q_{j}+\sum_{k \neq j}^{J} q_{k}\right) q_{j}-F q_{j}+(F-\tilde{S})\left(1-\omega_{j}\right) q_{j}$

From (2), the profit of a firm is the sum of the real profit under full hedging and the financial payoff from not hedging a fraction $1-\omega_{j}$ of the input, i.e., the terms $P\left(q_{j}+\sum_{k \neq j}^{J} q_{k}\right) q_{j}-F q_{j}$ and $(F-\tilde{S})\left(1-\omega_{j}\right) q_{j}$, respectively. Although expressions (1) and (2) are equivalent, expression (2) is an alternative decomposition of profits, which offers another interpretation for the behavior of the firm. That is, the firm purchases all input for production in the futures market and takes advantage of any opportunities in expected returns between spot and futures markets. In our paper, we refer to speculation as in Holthausen (1979) and Feder et al. (1980).

\subsection{Assumptions}

Each firm is managed by a risk-averse officer (e.g., the CEO) whose objective is to maximize the firm's expected utility of profit over output and hedge coverage. The next four assumptions hold for the remainder of the paper.

Assumption 2.1. The utility function for profit $\pi$ is $u(\pi)$ such that $u^{\prime}>$ $0, u^{\prime \prime}<0$.

Assumption 2.2. Inverse demand $p=P(Q), Q \equiv \sum_{k=1}^{J} q_{k}$ is twice continuously differentiable such that

1. $P(0)<\infty$,

2. $P^{\prime}(Q)<0$ in the interval for which $p=P(Q)>0$, and

3. $P^{\prime \prime}(Q) q_{j}+P^{\prime}(Q)<0$ for all $j$.

Assumption 2.3. The p.d.f. of the random spot price $\tilde{S}$ is $\phi(S)$ for $S \in$ $(0, P(0))$.

Assumption 2.4. $F \in(0, P(0))$. 
We make three comments regarding our assumptions. First, Assumptions 2.1 and 2.2 yield a unique number of firms entering the market in the first stage of the game and ensures the existence of a unique Cournot equilibrium in the second stage. In particular, Condition 3 in Assumption 2.2 ensures that a firm's best-response function to the total output of the other firms have a nonpositive slope greater than -1. Second, from Assumptions 2.3 and 2.4, there always exists an output price high enough to cover the input cost using both input markets so that trivial cases for which the output market does not exist are ignored. Third, Assumption 2.4 implies that no restriction is imposed on the futures price. ${ }^{19}$ Specifically, in addition to having an actuarially fair futures price, i.e., $F=\mathbb{E} \tilde{S}$ where $\mathbb{E}$ is the expectation operator, the futures market may be either in normal backwardation (i.e., $F<\mathbb{E} \tilde{S})$ or in contango (i.e., $F>\mathbb{E} \tilde{S}) .^{20}$

\subsection{Definition of Equilibrium}

Definition 2.5 provides the free-entry equilibrium with access to the futures market, i.e., $\omega_{j} \in \mathbb{R}$. The term free entry means that there is no institutional constraint on firms entering the market, i.e., firms may enter the market in response to profit opportunities. The equilibrium consists of the number of firms entering the industry, $J^{*}$; the Cournot strategies, $\left\{q^{*}\left(J^{*}\right), \omega^{*}\left(J^{*}\right)\right\}$; and the output price, $p^{*}\left(J^{*}\right) .^{21}$ To simplify the notation, the integral over $S$ is replaced by the expectation operator $\mathbb{E}$ over the random spot price $\tilde{S}$. Note that we choose to model the entry cost as an opportunity entry cost. Here, $K>0$ is the entry cost and $u(K)$ is the utility level corresponding to the

\footnotetext{
${ }^{19}$ To discard uninteresting cases in which the firms do not produce, the futures price is restricted to be below the reservation price of the output.

${ }^{20}$ The futures markets for oil were in contango in 2011. This situation is generally explained by the recent political situation in Arab countries. Other futures markets (e.g., gold and silver) were in normal backwardation during the same period. See http://www.zacks.com/stock/news/57493/Backwardation-and-Contango.

${ }^{21}$ Since the equilibrium is symmetric, the summation operator is no longer needed, i.e., $\sum_{k \neq j}^{J^{*}} q^{*}\left(J^{*}\right)=\left(J^{*}-1\right) q^{*}\left(J^{*}\right)$.
} 
best alternative activity. ${ }^{22}$

Definition 2.5. The tuple $\left\{J^{*}, q^{*}\left(J^{*}\right), \omega^{*}\left(J^{*}\right), p^{*}\left(J^{*}\right)\right\}$ is an equilibrium if

1. For all $j$, given $J^{*} \geq 1$ and the strategies $\left\{q^{*}\left(J^{*}\right), \omega^{*}\left(J^{*}\right)\right\}$ of firm $k \neq j$, $q^{*}\left(J^{*}\right)$ and $\omega^{*}\left(J^{*}\right)$ solve

$$
\max _{q_{j} \geq 0, \omega_{j} \in \mathbb{R}} \mathbb{E} u\left(\pi\left(J^{*}, q_{j}, \omega_{j},\left(J^{*}-1\right) q^{*}\left(J^{*}\right), \tilde{S}, F\right)\right) .
$$

2. Given $J^{*} \geq 1$ and $q^{*}\left(J^{*}\right), p^{*}\left(J^{*}\right)=P\left(J^{*} q^{*}\left(J^{*}\right)\right)$.

3. Given the strategies $\left\{q^{*}\left(J^{*}\right), \omega^{*}\left(J^{*}\right)\right\}, J^{*} \geq 0$ is an integer that satisfies

$$
\mathbb{E} u\left(\pi\left(J^{*}, q^{*}\left(J^{*}\right), \omega^{*}\left(J^{*}\right),\left(J^{*}-1\right) q^{*}\left(J^{*}\right), \tilde{S}, F\right)\right) \geq u(K)
$$

for $J^{*} \geq 1$, and

$$
\mathbb{E} u\left(\pi\left(J^{*}+1, q^{*}\left(J^{*}+1\right), \omega^{*}\left(J^{*}+1\right), J^{*} q^{*}\left(J^{*}+1\right), \tilde{S}, F\right)\right)<u(K)
$$

for $J^{*} \geq 0$.

From Definition 2.5, Conditions 1 and 2 define the Cournot equilibrium at stage 2 of the game. Condition 3 is related to the entry decision at stage 1. Specifically, the equilibrium number of firms in the industry is such that, from (6), each entering firm receives an expected utility weakly greater than the utility derived from the best alternative activity, and, from (7), further entry yields an expected utility strictly smaller than the utility derived from the best alternative activity.

In our model, the firms do not enter the product market in order to have access to the futures market. Their main expertise is to offer goods and

${ }^{22}$ More generally, (6) and (7) could have been replaced by

$$
\mathbb{E} u\left(\pi\left(J^{*}, q^{*}\left(J^{*}\right), \omega^{*}\left(J^{*}\right),\left(J^{*}-1\right) q^{*}\left(J^{*}\right), \tilde{S}, F\right)-K\right) \geq \bar{u}
$$

and

$$
\mathbb{E} u\left(\pi\left(J^{*}+1, q^{*}\left(J^{*}+1\right), \omega^{*}\left(J^{*}+1\right), J^{*} q^{*}\left(J^{*}+1\right), \tilde{S}, F\right)-K\right)<\bar{u}
$$

where $K$ is the setup cost and $\bar{u}$ is the opportunity cost. Our approach simplifies the analysis and has no bearing on the results. 
services in the output market. In other words, if the firms do not produce, they have no need or demand for futures contracts. The firms face a risk emanating from the product market and, due to risk aversion, they develop a demand for financial products. However, the firms are not on the supply side of financial markets because they do not have any expertise to enter into the financial market and to become an investment bank or an insurance company. For example, they do not have the actuarial expertise to compute insurance premiums for pure or accident risks or to underwrite debt contracts or derivative products. ${ }^{23}$ Hence, these firms have no intention or ability to trade financial assets if they do not enter the product market.

\section{Equilibrium and Separation}

In this section, we provide a general characterization of the free-entry equilibrium with access to the futures market. We also discuss the effect of entry on the separation property as defined in the literature (Danthine, 1973; Holthausen, 1979; Feder et al., 1980; Viaene and Zilcha, 1998).

Definition 3.1. There is separation when production and output price are independent of uncertainty and risk aversion.

We show that, whenever the free-entry equilibrium exists and the futures price is not actuarially fair, the entry decision links production and output price to the distribution of the spot price as well as risk aversion. We proceed in two steps. We first show that the separation property holds at the second stage of the game, i.e., for a given number of firms. We then show that, once the number of firms is endogenized, the separation property no longer

\footnotetext{
${ }^{23}$ According to Freixas and Rochet (2008), banks differ from other firms because they have expertise for managing loans and deposits, for choosing their level of monitoring of different clients and for choosing their level of investment in specific relationships with their clients. These specificities are forms of entry barriers in the banking industry. Banks also have expertise in risk management of large portfolios of derivatives with market, liquidity, and default risks. For an empirical analysis on scale economies in the provision of underwriting services by banks and related entry barriers in the banking industry, see Santos and Tsatsarinis (2003).
} 
holds because both uncertainty and risk aversion alter market concentration, which, in turn, affects both production and output price.

Proposition 3.2 provides the firm's production and hedge coverage in the Cournot equilibrium at the second stage of the game, i.e., for a given number of firms. In equilibrium, the firms always produce regardless of the type of financial activity, i.e., $q^{*}(J)>0$.

Proposition 3.2. Suppose that there are $J \geq 1$ firms in the industry at the second stage of the game. Then, there exists a unique Cournot-Nash equilibrium. In equilibrium, $q^{*}(J)>0$ and $\omega^{*}(J)$ are defined respectively by

$$
P^{\prime}\left(J q^{*}(J)\right) q^{*}(J)+P\left(J q^{*}(J)\right)-F=0
$$

and

$$
\mathbb{E}\left[(F-\tilde{S}) \cdot u^{\prime}\left(\Pi^{*}+(F-\tilde{S})\left(1-\omega^{*}(J)\right) q^{*}(J)\right)\right]=0,
$$

$\Pi^{*} \equiv P\left(J q^{*}(J)\right) q^{*}(J)-F q^{*}(J)$.

Proof. See Appendix A.

Using Proposition 3.2, Remark 3.3 states the separation property at the second stage of the game. That is, the distribution of the spot price and risk aversion have no effect on production and output price. The futures price is the sole driving force for production because, from (8), the marginal revenue of output is equal to the futures price. ${ }^{24}$ The separation property is consistent with the case of perfect competition either when there is uncertainty about the output price (Ethier, 1973; Danthine, 1973; Holthausen, 1979; Feder et al., 1980) or the input price (Holthausen, 1979; Katz and Paroush, 1979; Paroush

\footnotetext{
${ }^{24}$ Note that at stage 2 of the game, the separation property holds unconditionally because firms may either hedge or engage in speculation. Assuming CARA preferences, a linear demand, and a normally distributed spot price, online Appendix 4 shows that if firms can only hedge (i.e., have restricted access to the futures market), then production and output price are only conditionally independent of uncertainty and risk aversion. That is, conditional on hedging, production and output price remains independent of uncertainty and risk aversion. However, the upper bound of the range of futures prices yielding hedging is increasing in the mean and the variance of the spot price as well as risk aversion.
} 
and Wolf, 1992) as long as there is no other source of uncertainty (e.g., uncertainty in production or basis risk).

Remark 3.3. From (8), at the second stage of the game, production and output price are independent of uncertainty and risk aversion.

Having shown that separation occurs when there is no entry, we next show that, when the firms make a decision on entry, the futures price is no longer the driving force for the production decision. In fact, there is always nonseparation because the distribution of the spot price and the utility function have an effect on the production decision (and, thus, the output price) through the number of firms entering the industry. We proceed as follows. We first characterize the number of firms entering the market at the first stage of the game (Proposition 3.4). We then provide a comparative analysis of the effect of changes in the distribution of the spot price for the input as well as changes in risk aversion on the number of firms (Propositions 3.5 and 3.6). This comparative analysis establishes directly the nonseparation result on production and output price (Proposition 3.7).

Proposition 3.4 states that there exists a unique free-entry equilibrium with access to the futures market as long as the entry cost is not too high to prevent at least one firm from entering the industry. The entry cost must also be not too low to ensure a finite number of entering firms.

Proposition 3.4. Suppose that

$$
\begin{aligned}
& \lim _{J \rightarrow \infty} \mathbb{E} u\left(P\left(J q^{*}(J)\right) q^{*}(J)-F q^{*}(J)+(F-\tilde{S})\left(1-\omega^{*}(J)\right) q^{*}(J)\right)<u(K) \\
& \leq \mathbb{E} u\left(P\left(q^{*}(1)\right) q^{*}(1)-F q^{*}(1)+(F-\tilde{S})\left(1-\omega^{*}(1)\right) q^{*}(1)\right)
\end{aligned}
$$

Then, there exists a unique equilibrium with $1 \leq J^{*}<\infty$ firms in the industry such that $J^{*}=\left\lfloor N^{*}\right\rfloor$ where $N^{*}$ is implicitly defined by

$$
\mathbb{E} u\left(P\left(N q^{*}(N)\right) q^{*}(N)-F q^{*}(N)+(F-\tilde{S})\left(1-\omega^{*}(N)\right) q^{*}(N)\right)=u(K)
$$

evaluated at $N=N^{*}$.

Proof. See Appendix A. 
Propositions 3.5 and 3.6 state that, when the futures price is not actuarially fair, market concentration depends on uncertainty and risk aversion. ${ }^{25}$ In particular, from Proposition 3.5, an increase in the mean of $\tilde{S}$ weakly decreases (weakly increases) the number of firms when the futures market is contango (normal backwardation). Indeed, when the market is contango (normal backwardation), the firms are net buyers (net sellers) on the spot market for the input. Hence, an increase in the mean of the spot price for the input decreases (increases) the expected utility in the second stage, which induces less (more) firms to enter the industry.

A riskier spot price weakly decreases the number of firms in the industry. ${ }^{26}$ From Proposition 3.6, an increase in risk aversion also weakly decreases the number of firms in the industry. The similar result comes from the fact that a mean-preserving increase in risk or an increase in risk aversion both reduce the expected utility in the second stage, which induces less firms to enter the industry.

We begin with the effect of uncertainty on market concentration. To that end, suppose that $\phi(S)=\psi(S ; m, r)$ where an increase in $m$ implies an increase in the mean of $\tilde{S}$ whereas an increase in $r$ implies a mean-preserving increase in the risk of $\tilde{S}$ in the sense of Rothschild and Stiglitz (1971).

Proposition 3.5. Suppose that $\phi(S)=\psi(S ; m, r)$. Then, for $F \neq \mathbb{E} \tilde{S}$,

1. An increase in the mean of $\tilde{S}$ weakly decreases (weakly increases) $J^{*}$ when $F>\mathbb{E} \tilde{S}(F<\mathbb{E} \tilde{S})$.

2. A mean-preserving increase in the risk of $\tilde{S}$ weakly decreases $J^{*}$.

Proof. See Appendix A.

Proposition 3.6 states the effect of increasing risk aversion on the number of firms in the industry. Using the notation in Diamond and Stiglitz (1974), suppose that $u(\pi)=v(\pi ; \rho)$ with $v_{1}>0, v_{11}<0$ and $\partial\left(-v_{11}(\pi ; \rho) / v_{1}(\pi ; \rho)\right) / \partial \rho>$ 0 . Hence, an increase in $\rho$ implies an increase in risk aversion.

\footnotetext{
${ }^{25}$ If $F=\mathbb{E} \tilde{S}$, then market concentration is independent of uncertainty and risk aversion.

${ }^{26} \mathrm{We}$ adopt the expression weakly decrease or weakly increase because $J^{*}$ is an integer.
} 
Proposition 3.6. Suppose that $u(\pi)=v(\pi ; \rho)$ such that $v_{1}>0, v_{11}<0$ and $\partial\left(-v_{11}(\pi ; \rho) / v_{1}(\pi ; \rho)\right) / \partial \rho>0$. Then, for $F \neq \mathbb{E} \tilde{S}$, an increase in risk aversion weakly decreases $J^{*}$.

Proof. See Appendix A.

Using Propositions 3.5 and 3.6, Proposition 3.7 states that as long as the futures price is not actuarially fair, the separation property does not hold when entry is considered. The negative effect of mean (in a contango situation), riskiness, or risk aversion on the number of firms implies that the remaining firms can exercise more market power. Specifically, when there is access to the futures market, higher riskiness induces each remaining firm to produce more. However, while per-firm production increases along with more riskiness, the number of firms decreases, which is the dominant effect, and the equilibrium output price unambiguously increases along with an increase in the riskiness of the spot price. The result also holds for an increase in the mean of the spot price in a contango situation or an increase in risk aversion.

Proposition 3.7. Suppose that the futures price is not actuarially fair, i.e., $F \neq \mathbb{E} \tilde{S}$. Then, when entry is endogenized, production and output price depend on uncertainty and risk aversion. In particular,

1. An increase in the mean of $\tilde{S}$ weakly increases (weakly decreases) $q^{*}\left(J^{*}\right)$ and $p^{*}\left(J^{*}\right)$ when $F>\mathbb{E} \tilde{S}(F<\mathbb{E} \tilde{S})$.

2. A mean-preserving increase in the risk of $\tilde{S}$ or an increase in risk aversion weakly increases $q^{*}\left(J^{*}\right)$ and $p^{*}\left(J^{*}\right)$.

Proof. From (39) and (40), $q^{*}\left(J^{*}\right)$ and $p^{*}\left(J^{*}\right)=P\left(J^{*} q^{*}\left(J^{*}\right)\right)$ are both decreasing in $J^{*}$. Using Proposition 3.5 and 3.6 yields the results stated in Proposition 3.7.

The result stated in Proposition 3.7 is in sharp contrast to the separation result obtained in the literature in the absence of another source of uncertainty (e.g., uncertainty in production or basis risk). In other words, once firms are allowed to make entry decisions, the futures price is no longer the 
driving force for the production decision (even with one source of uncertainty). Indeed, conditional on the number of firms, each firm is able to fully adjust production in such a way that it is independent of uncertainty and risk aversion. When firms also make entry decisions, production decisions becomes less flexible. Hence, the endogenization of the number of firms in an industry with a cost of entry yields nonseparation. ${ }^{27}$

\section{The Effect of Access to Futures Market}

In this section, we study the effect of access to the futures market on entry. ${ }^{28}$ To simplify the discussion, we make the following restrictions. Managers' risk preferences on profit exhibit constant absolute risk aversion. Output demand is linear and the firms' beliefs about the spot price for the input are normally distributed. These restrictions are consistent with Assumptions 2.1, 2.2 , and 2.3 except for the fact that the support of the spot price is the real line. Although the spot price can be negative, the values of the parameters of the model can be restricted to ensure that the probability of such events be arbitrarily close to zero. Moreover, it turns out that, by assuming a positive mean of the spot price, equilibrium values for the number of firms, the production, and the output price are always positive.

Formally, our restrictions are as follows. The coefficient of absolute risk aversion is $\alpha>0 .{ }^{29}$ Inverse demand is linear, i.e.,

$$
P\left(\sum_{k=1}^{J} q_{k}\right)=\theta-\gamma \sum_{k=1}^{J} q_{k}
$$

where $\theta, \gamma>0$ are demand parameters. The spot price for the input is normally distributed, i.e., $\tilde{S} \sim N\left(\mu_{S}, \sigma_{S}^{2}\right), \mu_{S} \in(0, \theta)$. Given our restrictions, the certainty equivalent has a closed-form solution. Using (2), the certainty

\footnotetext{
${ }^{27}$ If entry were not costly, the number of firms would be infinity in our case. In the limit, total production and output price would be independent of the distribution of the spot price and risk aversion.

${ }^{28}$ The effect of access to the futures market on production and output price is discussed in online Appendix 7.

${ }^{29} \mathrm{In}$ other words, the utility function for profit $\pi$ is exponential: $u(\pi)=-e^{-\alpha \pi}$.
} 
equivalent of firm $j$ is

$$
\begin{aligned}
C E\left(J, q_{j}, \omega_{j}, \sum_{k \neq j}^{J} q_{k}\right)= & P\left(q_{j}+\sum_{k \neq j}^{J} q_{k}\right) q_{j}-\mu_{S}\left(1-\omega_{j}\right) q_{j} \\
& -F \omega_{j} q_{j}-\alpha \sigma_{S}^{2}\left(1-\omega_{j}\right)^{2} q_{j}^{2} / 2
\end{aligned}
$$

as shown in online Appendix 2.

Since $J^{*}=\left\lfloor N^{*}\right\rfloor$ is an integer, we use the continuous variable $N^{*}$ whenever we need to approximate the effect of any parameter on $J^{*}$ by computing the partial derivative of $N^{*}$ with respect to that parameter. In addition, we use $N^{*}$ instead of $J^{*}$ to approximate the remaining equilibrium variables, e.g., $q^{*}\left(J^{*}\right) \approx q^{*}\left(N^{*}\right)$. This approximation has no bearing on the results since the number of firms is not bounded between two integers. Hence, changes in $N^{*}$ are informative about changes in $J^{*}{ }^{30}$

We first characterize the equilibrium with and without access to the futures market. We then compare the equilibrium values under access and under no access to the futures market on entry. The effect of financial access on production and output price is found in online Appendix 7.

\subsection{Equilibrium Characterization}

Access to Financial Market. Proposition 4.1 states the unique free-entry equilibrium with access to the futures market.

Proposition 4.1. For $F \in(0, \theta)$, there exists a unique equilibrium with $1 \leq J^{*}<\infty$ firms in the industry if and only if

$$
\frac{\left(F-\mu_{S}\right)^{2}}{2 \alpha \sigma_{S}^{2}}<K \leq \frac{(\theta-F)^{2}}{4 \gamma}+\frac{\left(F-\mu_{S}\right)^{2}}{2 \alpha \sigma_{S}^{2}}
$$

In equilibrium, $J^{*}=\left\lfloor N^{*}\right\rfloor$ firms enter the industry where

$$
N^{*}=\frac{\theta-F}{\sqrt{\left(K-\frac{\left(F-\mu_{S}\right)^{2}}{2 \alpha \sigma_{S}^{2}}\right) \gamma}}-1 .
$$

\footnotetext{
${ }^{30}$ Moreover, since the equilibrium is symmetric, the summation operator is not present in the equilibrium values.
} 
Each firm produces

$$
q^{*}\left(J^{*}\right) \approx q^{*}\left(N^{*}\right)=\sqrt{\left(K-\frac{\left(F-\mu_{S}\right)^{2}}{2 \alpha \sigma_{S}^{2}}\right) / \gamma}
$$

at output price

$$
p^{*}\left(J^{*}\right) \approx p^{*}\left(N^{*}\right)=\sqrt{\left(K-\frac{\left(F-\mu_{S}\right)^{2}}{2 \alpha \sigma_{S}^{2}}\right) \gamma}+F .
$$

Hedge coverage is

$$
\omega^{*}\left(J^{*}\right) \approx \omega^{*}\left(N^{*}\right)=1-\frac{\sqrt{\gamma}\left(F-\mu_{S}\right)}{\alpha \sigma_{S}^{2} \sqrt{K-\frac{\left(F-\mu_{S}\right)^{2}}{2 \alpha \sigma_{S}^{2}}}} .
$$

Proof. See online Appendix 3.

We now discuss several properties of the equilibrium. From condition (14) in Proposition 4.1, there exists an equilibrium with access to the futures market as long as the entry cost is not too high to prevent at least one firm from entering the industry. The entry cost must also be not too low to ensure a finite number of entering firms.

Condition (14) is depicted in Figure 2, where $F \in(0, \theta)$ is on the $x$-axis, and $K>0$ is on the $y$-axis. ${ }^{31}$ The two convex lines depict the lower and upper bounds in (14). ${ }^{32}$ Hence, the darker shaded area between the two curves encompasses the points $\{K, F\}$ for which the equilibrium exists, and, in particular, a finite number of firms enter the industry. Note that entry may occur for all values of $F$, whether the futures market is normal backwardation $\left(F \in\left(0, \mu_{S}\right)\right)$, actuarially fair $\left(F=\mu_{S}\right)$, or contango $\left(F>\mu_{S}\right)$. Note as well that, while the upper and lower bounds of (14) depends on the mean and variance of the spot price (and risk aversion), the darker shaded area between

\footnotetext{
${ }^{31}$ To generate Figure 2 , we set $\{\theta, \gamma\}=\{7,1\}$, and $\left\{\mu_{S}, \sigma_{S}^{2}, \alpha\right\}=\{2,1,1\}$. Although Figure 2 is generated with specific values, the shapes of the curves hold in general. The same comment applies to all figures.

${ }^{32}$ Note that the lower and upper bounds do not require to be approximated. Hence, we use the variable $J^{*}$ in Figure 2.
} 


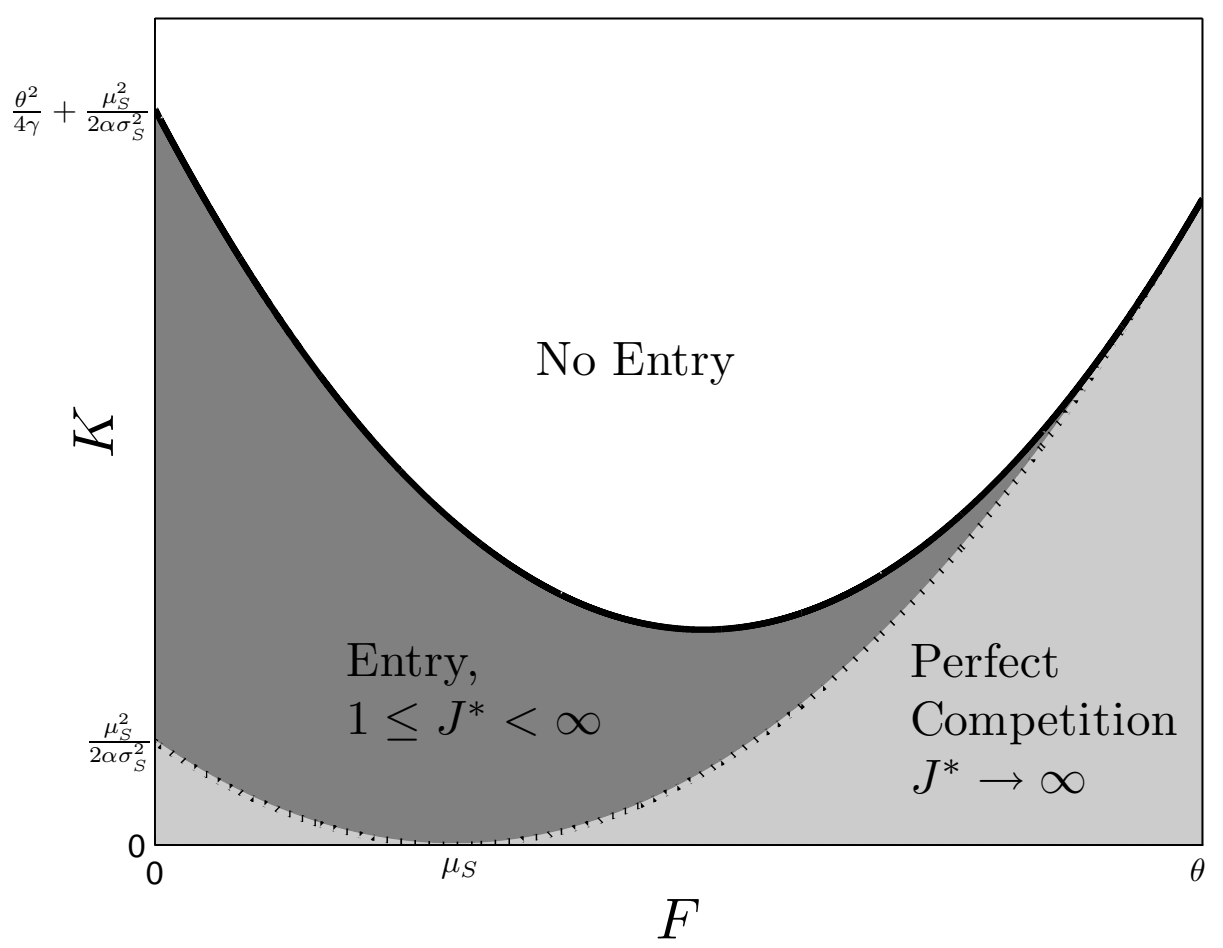

Figure 2: Entry, Access to the Futures Market

the two curves,

$$
\int_{0}^{\theta}\left(\frac{(\theta-x)^{2}}{4 \gamma}+\frac{\left(x-\mu_{S}\right)^{2}}{2 \alpha \sigma_{S}^{2}}-\frac{\left(x-\mu_{S}\right)^{2}}{2 \alpha \sigma_{S}^{2}}\right) \mathrm{d} x=\frac{\theta^{3}}{12 \gamma}
$$

is unaffected by changes in the mean and variance of the spot price as well as risk aversion. In other words an increase in any of these three parameters does not reduce the possibility of entry. Below the lowest convex curve, there is no equilibrium with a finite number of firms. In other words, all potential entrants have an incentive to enter. Because unlimited entry (with $K>0$ ) is solely due to speculative motives, we delay our discussion about the limiting case (i.e., $J^{*} \rightarrow \infty$ ).

Having discussed the condition for entry, we provide information about the types of financial activities in which the firms engage in equilibrium. Proposition 4.2 states that, whenever the equilibrium exists, the firms may 
hedge or speculate (or both) depending on the structure of the futures market and the value of the entry cost.

Proposition 4.2. Suppose that (14) holds. Then, in equilibrium,

1. For $F \in\left(0, \mu_{S}\right)$, the firms fully hedge production and, at the same time, speculate by buying in the futures market to sell in the spot market, i.e., $\omega^{*}\left(N^{*}\right)>1$.

2. For $F=\mu_{S}$, the firms fully hedge production, i.e., $\omega^{*}\left(N^{*}\right)=1$.

3. For $F \in\left(\mu_{S}, \theta\right)$, there are three exclusive outcomes.

(a) The firms partially hedge, i.e., $\omega^{*}\left(N^{*}\right) \in(0,1)$.

(b) The firms do not access the futures markets, i.e., $\omega^{*}\left(N^{*}\right)=0$.

(c) The firms speculate by buying in the spot market to sell in the futures market, i.e., $\omega^{*}\left(N^{*}\right)<0$.

Proof. See online Appendix 3.

Figure 3 illustrates Proposition 4.2 by providing information about the firms' financial activity when there is a finite number of firms entering the industry. ${ }^{33}$ Note that Figure 3 uses the value of $\omega^{*}\left(N^{*}\right)$ (as provided by (18)) to approximate $\omega^{*}\left(J^{*}\right)$. If the futures market is in normal backwardation (i.e., $F<\mu_{S}$ ), then the firms fully hedge and speculate. That is, the input is purchased only on the futures market, some of which is used for production and the remaining is sold on the spot market. Whenever the futures price is actuarially fair (i.e., $F=\mu_{S}$ ), the firms fully hedge. See the dashed vertical line in Figure 3 for which $\omega^{*}\left(N^{*}\right)=1$.

A contango futures market (i.e., $F>\mu_{S}$ ) yields either partial hedging or speculation (with no hedging) depending on the value of the entry cost and the futures price. The division between these two outcomes is depicted by the dashed increasing convex line $K=\frac{\left(2 \gamma+\alpha \sigma_{S}^{2}\right)\left(F-\mu_{S}\right)^{2}}{2 \alpha^{2} \sigma_{S}^{4}}$, intersecting with the

\footnotetext{
${ }^{33}$ Figures 2 and 3 are generated using the same parameter values.
} 


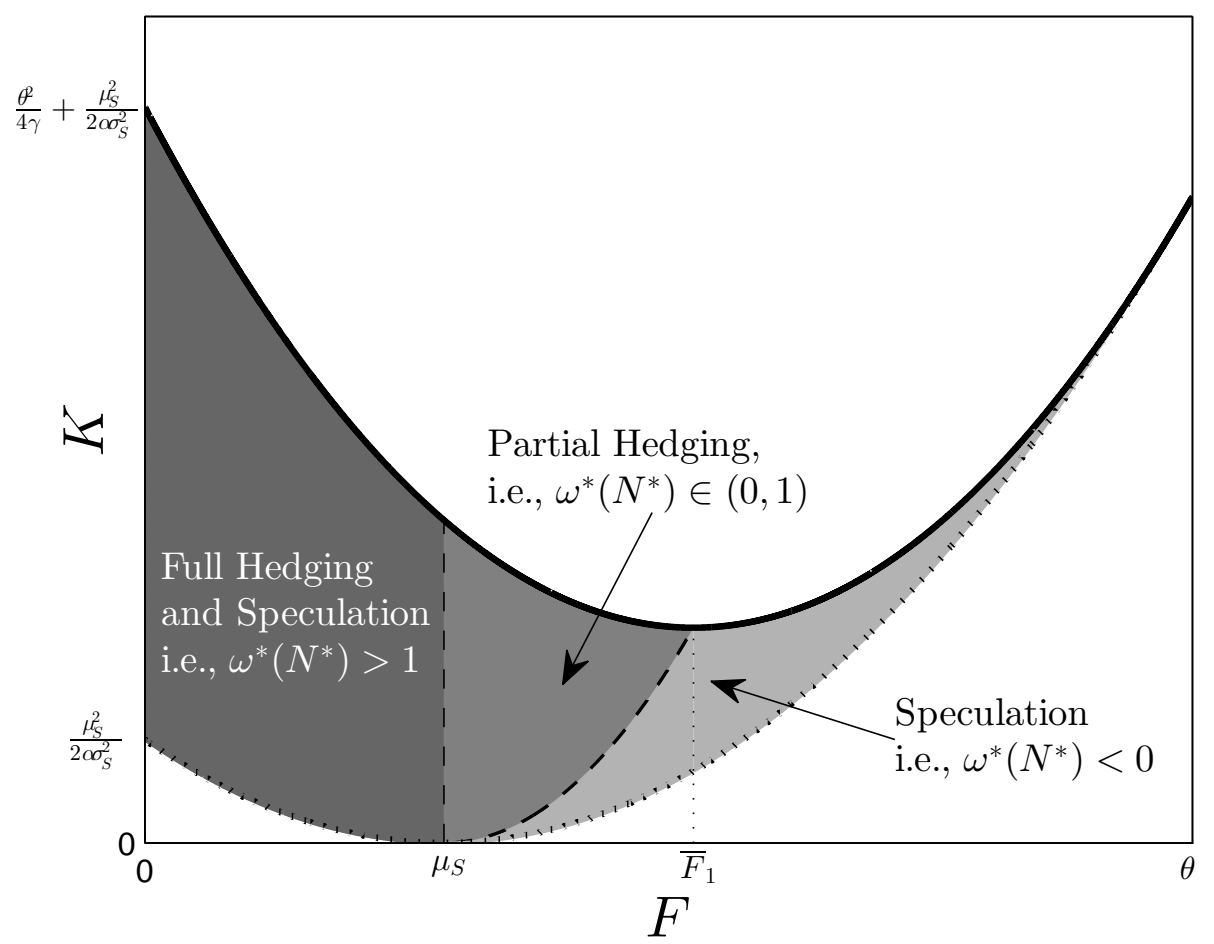

Figure 3: Financial Activity, Access to the Futures Market

minimum of the upper bound for $K$ in (14), i.e., when $F=\bar{F}_{1} \equiv \frac{2 \gamma \mu_{S}+\alpha \sigma_{S}^{2} \theta}{2 \gamma+\alpha \sigma_{S}^{2}} .34$ From Figure 3, in a contango situation, hedging is possible only for lower values of the futures price, while speculation (buying from the spot market to sell on the futures market) can occur at any futures price as long as the entry cost is low enough.

Remark 4.3. For $F \in\left[\bar{F}_{1}, \theta\right)$, hedging is no longer chosen regardless of the value of the entry cost

The entry cost influences the type of financial activity. In Figure 3, consider a point $\{K, F\}$ in the area for partial hedging (i.e., $\omega^{*}\left(N^{*}\right) \in(0,1)$ ). A decrease in the entry cost while keeping the futures price constant eventually leads to a switch from hedging to speculation. This is due to the fact that a

\footnotetext{
${ }^{34}$ The points $\{K, F\}$ on the dashed increasing line that intersects the upper bound of (14) at its minimum refer to cases for which the firms do not access the futures market, i.e., $\omega^{*}\left(N^{*}\right)=0$.
} 

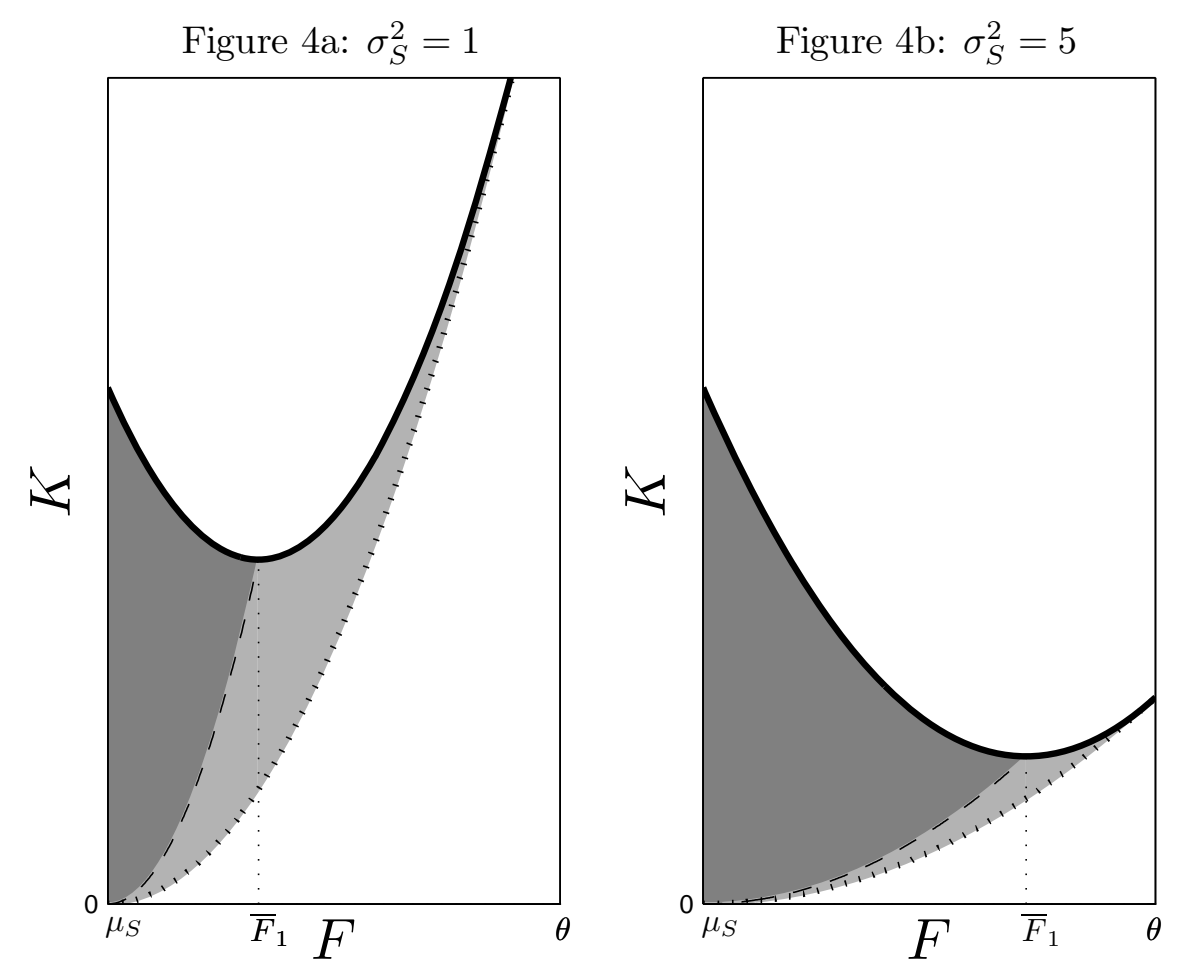

Figure 4: Financial Activity, Hedging vs. Speculation

lower $K$ yields more entry, which reduces profit from selling the output, and, thus, raises the opportunity cost of hedging (instead of speculating) under contango.

Remark 4.4. For $F \in\left(\mu_{S}, \bar{F}_{1}\right]$, a lower entry cost can induce the firms not to hedge, but to engage in speculation instead.

Finally, hedging becomes more likely under contango along with an increase in the variance of the spot price or risk aversion. This is illustrated in Figure 4, which shows that an increase in the variance of the spot price moves $\bar{F}_{1} \equiv \frac{2 \gamma \mu_{S}+\alpha \sigma_{S}^{2} \theta}{2 \gamma+\alpha \sigma_{S}^{2}}$ to the right, which increases the darker shaded area (partial hedging) and reduces the lighter shaded area (speculation). ${ }^{35}$

Remark 4.5. For $F \in\left[\mu_{S}, \theta\right)$, an increase (decrease) in $\sigma_{S}^{2}$ or $\alpha$ makes it more likely for hedging (speculation) to occur.

\footnotetext{
${ }^{35}$ To generate Figure 4 , we set $\{\theta, \gamma\}=\{10,1\}$ and $\left\{\mu_{S}, \alpha\right\}=\{5,1\}$.
} 
It remains to discuss the limiting case below the lowest convex curve in Figure 2. Specifically, the lighter shaded area in Figure 2 combines the points $\{K, F\}$ for which entry is always beneficial regardless of the number of firms active in the market. In other words, the stage- 2 certainty equivalent is high enough to cover the entry cost for any number of firms, which yields the case of perfect competition. Due to unlimited entry, the profit from the output sector approaches zero (i.e., the perfect competition outcome drives the output price to the marginal cost), while the firms engage in speculation to generate revenue from the financial sector. Consistent with Figure 2, this is only possible when the futures price is not actuarially fair. From Figure 2, there are two outcomes under the limiting case of perfect competition (i.e., in the lighter shaded area). The firms speculate by selling futures contracts under contango (i.e., $F>\mu_{S}$ ), while buying them under normal backwardation (i.e., $F<\mu_{S}$ ). Although $K>0$, speculation on the futures market makes it possible for the output market to approach perfect competition in the limit.

Proposition 4.6. For $F \in(0, \theta), F \neq \mu_{S}$, and $0<K \leq \frac{\left(F-\mu_{S}\right)^{2}}{2 \alpha \sigma^{2}}, J^{*} \rightarrow \infty$ yielding the perfectly competitive outcome in the output sector. Further, firms always engage in speculation in the futures market.

Proof. Suppose that $F \in(0, \theta), F \neq \mu_{S}$ and $0<K \leq \frac{\left(F-\mu_{S}\right)^{2}}{2 \alpha \sigma^{2}}$. From (17) in online Appendix 3, $C E^{*}(J)=\frac{(\theta-F)^{2}}{(1+J)^{2} \gamma}+\frac{\left(F-\mu_{S}\right)^{2}}{2 \alpha \sigma_{S}^{2}}>K$ for any $J$. Hence, $J^{*} \rightarrow$ $\infty$. From (12) and (13) in online Appendix $3, \lim _{J^{*} \rightarrow \infty} x^{*}\left(J^{*}\right)=\frac{F-\mu_{S}}{\alpha \sigma_{S}^{2}}$ and $\lim _{J^{*} \rightarrow \infty} y^{*}\left(J^{*}\right)=-\frac{F-\mu_{S}}{\alpha \sigma_{S}^{2}}$, while, from (14) and (16) in online Appendix 3, $\lim _{J^{*} \rightarrow \infty} q^{*}\left(J^{*}\right)=0$, and $\lim _{J^{*} \rightarrow \infty} p^{*}\left(J^{*}\right)=F \cdot 36$

No Access to Financial Market. Next, we turn to the characterization and discussion of the benchmark equilibrium when the firms have no access to the futures market. Proposition 4.7 characterizes the unique equilibrium. To clarify the analysis, the hat sign is used on equilibrium values when there is no access to the futures market.

\footnotetext{
${ }^{36}$ Recall that $q^{*}\left(J^{*}\right)=x^{*}\left(J^{*}\right)+y^{*}\left(J^{*}\right)$ where $x^{*}\left(J^{*}\right)$ is the amount of input purchased (or sold) in the spot market and $y^{*}\left(J^{*}\right)$ is the amount of input purchased (or sold) in the futures market.
} 
Proposition 4.7. Suppose that no firm has access to the futures market, i.e., the constraint $\omega_{j}=0$ holds for all $j$. Then, there exists a unique equilibrium with $1 \leq \hat{J}^{*}<\infty$ if and only if

$$
0<K \leq \hat{K} \equiv \frac{\left(\theta-\mu_{S}\right)^{2}}{2\left(2 \gamma+\alpha \sigma_{S}^{2}\right)} .
$$

In equilibrium, $\hat{J}^{*}=\left\lfloor N^{*}\right\rfloor$ firms enter the industry where

$$
\hat{N}^{*}=\frac{\left(\theta-\mu_{S}\right) \sqrt{2 \gamma+\alpha \sigma_{S}^{2}}}{\gamma \sqrt{2 K}}-\frac{\alpha \sigma_{S}^{2}}{\gamma}-1 .
$$

Each firm produces

$$
\hat{q}^{*}\left(\hat{J}^{*}\right) \approx \hat{q}^{*}\left(\hat{N}^{*}\right)=\frac{\sqrt{2 K}}{\sqrt{2 \gamma+\alpha \sigma_{S}^{2}}}
$$

at output price

$$
\hat{p}^{*}\left(\hat{J}^{*}\right) \approx \hat{p}^{*}\left(\hat{N}^{*}\right)=\mu_{S}+\frac{\sqrt{2 K}\left(\gamma+\alpha \sigma_{S}^{2}\right)}{\sqrt{2 \gamma+\alpha \sigma_{S}^{2}}} .
$$

Proof. See online Appendix 3.

Two comments about Proposition 4.7 are warranted. First, there exists an equilibrium as long as the entry cost is not too high to prevent at least one firm from entering the industry. ${ }^{37}$ Condition (20) is depicted in Figure 5, where $F \in(0, \theta)$ is on the $x$-axis, and $K>0$ is on the $y$-axis. Given that the firms do not access the futures market, the condition is independent of $F$ and the firms enter as long as $K \leq \hat{K} \equiv \frac{\left(\theta-\mu_{S}\right)^{2}}{2\left(2 \gamma+\alpha \sigma_{S}^{2}\right)} .{ }^{38}$

Second, access to the futures market alters the comparative analysis on the effect of uncertainty and risk preferences stated in Propositions 3.5

\footnotetext{
${ }^{37}$ An equilibrium with a finite number of firms exists as long as the entry cost is strictly greater than zero, otherwise an infinite number of potential firms would enter the industry.

${ }^{38}$ Unlike the case of access to the futures market, an increase in the mean or variance of the spot price, or an increase in risk aversion under no access to the futures market reduces the possibility of entry. Indeed, from (20), $\partial \hat{K} / \partial \mu_{S}<0, \partial \hat{K} / \partial \sigma_{S}^{2}<0, \partial \hat{K} / \partial \alpha<0$. See (19) for the case of access to the futures market.
} 


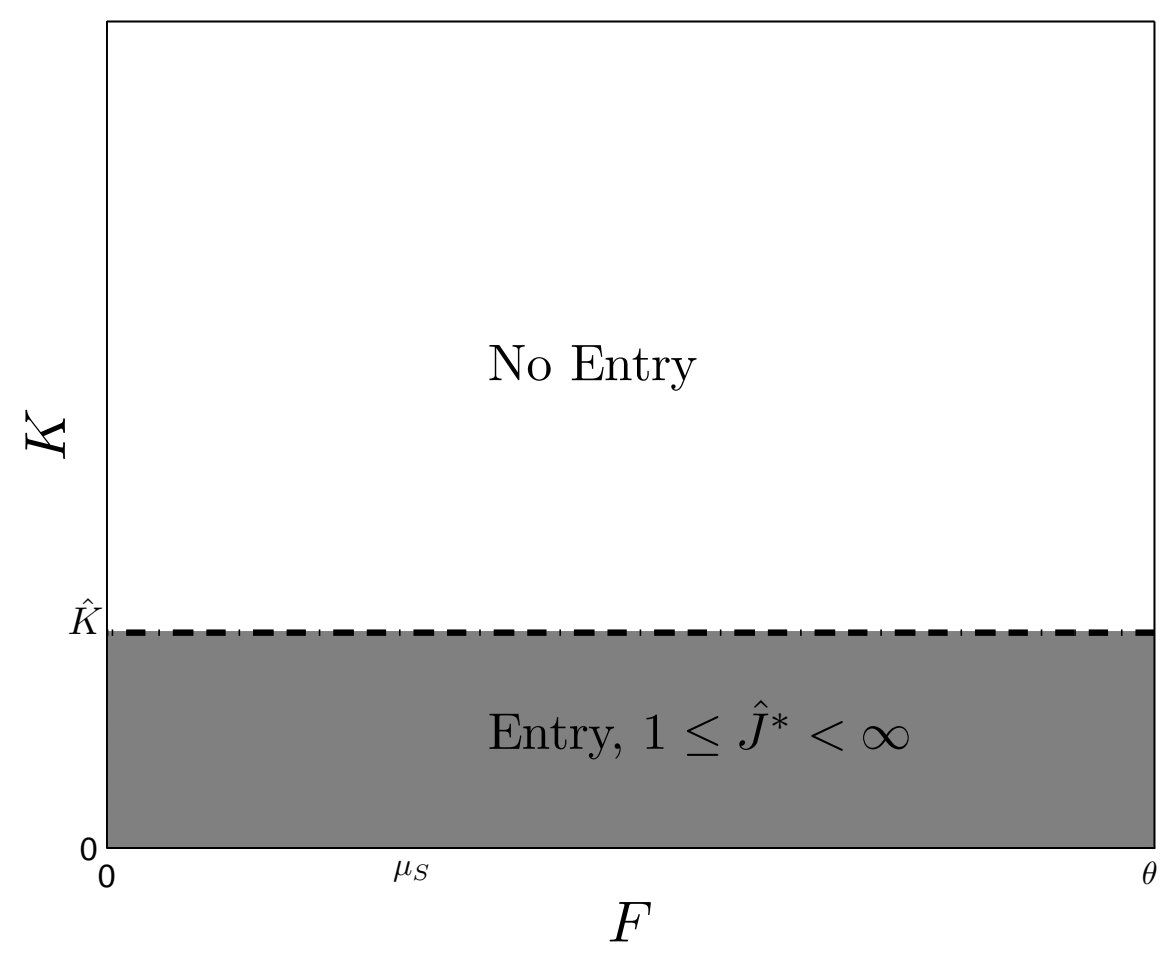

Figure 5: Entry, No Access to the Futures Market

and 3.6. Indeed, recall from Propositions 3.5 and 3.6 that a riskier spot price or an increase in risk aversion yields more production under access to the futures market. However, without financial access, an increase in risk or risk aversion induces the firms to produce less. That is, using (22), $\frac{\partial \hat{q}^{*}\left(\hat{N}^{*}\right)}{\partial \sigma_{S}^{2}}<0$, $\frac{\partial \hat{q}^{*}\left(\hat{N}^{*}\right)}{\partial \alpha}<0 .{ }^{39}$ In other words, financial access reverses the effect of riskiness and risk aversion on per-firm production.

\subsection{Entry}

Using Section 4.1, we can now study the effect of access to the futures market on entry. Before proceeding with the analysis, it is useful to recall how the

\footnotetext{
${ }^{39}$ The result without financial access is consistent with classical results obtained in a static environment (i.e., without entry decision) for perfect competition (Sandmo, 1971; Batra and Ullah, 1974) and quantity-setting monopoly (Leland, 1972).
} 
number of firms is determined in equilibrium. Given an entry cost $K>0$, the variables $N^{*}$ (the number of firms with access to the futures market) and $\hat{N}^{*}$ (i.e., the number of firms without access) are uniquely defined by

$$
C E^{*}\left(N^{*}\right)=K
$$

and

$$
\widehat{C E}^{*}\left(\hat{N}^{*}\right)=K
$$

respectively. Here, from (17) and (26) in online appendix 3, for any $N,{ }^{40}$

$$
\begin{aligned}
& C E^{*}(N)=\frac{(\theta-F)^{2}}{(1+N)^{2} \gamma}+\frac{\left(F-\mu_{S}\right)^{2}}{2 \alpha \sigma_{S}^{2}} \\
& \widehat{C E}^{*}(N)=\frac{\left(2 \gamma+\alpha \sigma_{S}^{2}\right)\left(\theta-\mu_{S}\right)^{2}}{2\left((1+J) \gamma+\alpha \sigma_{S}^{2}\right)^{2}}
\end{aligned}
$$

We provide two results about entry. First, access to the futures market allows the industry to bear a higher entry cost. Second, access to the futures markets can increase or decrease the number of firms entering the industry. These two seemingly contradictory results are in fact consistent with (24) and (25) and the behavior of the stage- 2 certainty equivalent as a function of the number of firms. Specifically, from (26) and (27), it is not always true that $C E^{*}(N)>\widehat{C E}^{*}(N)$ for all $N$. While $C E^{*}(N)$ and $\widehat{C E}^{*}(N)$ are both decreasing in $N$ and $C E^{*}(1)>\widehat{C E}^{*}(1)$, it is possible for $C E^{*}(N)$ to decrease more rapidly than $\widehat{C E}^{*}(N)$ and thus cross $\widehat{C E}^{*}(N)$ from above. Hence, for low values of the entry cost, a greater number of firms enter the industry when there is no access to the futures market. We now present our two results in detail.

Combining the information of Figures 2 and 5 into Figure 6 shows that (anticipated) access to the futures market can facilitate entry. In particular, for futures prices $F \in\left(\mu_{S}, \bar{F}_{1}\right], \bar{F}_{1} \equiv \frac{2 \gamma \mu_{S}+\alpha \sigma_{S}^{2} \theta}{2 \gamma+\alpha \sigma_{S}^{2}}$, partial hedging (without speculation) allows firms to enter for an entry cost above $\hat{K}$, which would have been otherwise impossible without access to the futures market. See area $A$

\footnotetext{
${ }^{40}$ Notation has been simplified to $C E^{*}(N) \equiv C E\left(N, q^{*}(N), \omega^{*}(N),(N-1) q^{*}(N)\right)$ and $\widehat{C E}^{*}(N) \equiv \widehat{C E}\left(N, \hat{q}^{*}(N), \hat{\omega}^{*}(N),(N-1) \hat{q}^{*}(N)\right)$.
} 
in Figure 6 such that $F \in\left(\mu_{S}, \bar{F}_{1}\right)$. Moreover, for futures prices $F \in\left(0, \mu_{S}\right)$ or $F \in\left(\bar{F}_{1}, \theta\right)$, speculation induces firms to enter for an entry cost above $\hat{K}$. See area $A$ such that $F \in\left(0, \mu_{S}\right)$ and area $B$ in Figure 6. As noted, Proposition 4.8 does not imply that access to the futures market always increases the stage-2 certainty equivalent. That is, from (26) and (27), it is not true that $C E^{*}(N)>\widehat{C E}^{*}(N)$ for all $N$. While one firm always benefits from access to the futures market (i.e., $C E^{*}(1)>\widehat{C E}^{*}(1)$ ), the presence of several firms interacting strategically may change the ordering. The reason is that access to the futures market reduces the cost of bearing risk and intensifies the Cournot game, which decreases stage-2 certainty equivalent. In some cases, the benefit from reducing risk through hedging is outweighed by the loss due to more intensive Cournot competition. This important point is discussed again when we explain the ambiguous effect of the futures price on the number of firms at the end of this section and in online Appendix 6 .

Proposition 4.8. Access to the futures market allows firms to bear a higher entry cost, i.e., entry of at least one firm is possible for $K>\hat{K}$. In particular, access to the futures market under partial hedging can generate higher expected profits, which compensates for a higher fixed cost of entry. ${ }^{41}$

While the industry can bear a higher entry cost, the effect of access to the futures market on the number of firms is ambiguous. To see this, we begin by comparing the number of firms under an actuarially fair futures price with the number of firms when there is no access to the futures market. Proposition 4.9 states that the number of firms is greater with an actuarially fair futures price as long as the entry cost is high enough.

Proposition 4.9. Suppose that $0<K<\hat{K} \equiv \frac{\left(\theta-\mu_{S}\right)^{2}}{2\left(2 \gamma+\alpha \sigma_{S}\right)}$. Then, $\left.N^{*}\right|_{F=\mu_{S}}>$ $\hat{N}^{*}$ if and only if

$$
\frac{\left(\theta-\mu_{S}\right)^{2}}{2\left(\sqrt{2 \gamma+\alpha \sigma_{S}^{2}}+\sqrt{2 \gamma}\right)^{2}}<K \leq \frac{\left(\theta-\mu_{S}\right)^{2}}{2\left(2 \gamma+\alpha \sigma_{S}^{2}\right)} .
$$

Proof. From (15) and (21), $\left.N^{*}\right|_{F=\mu_{S}}>\hat{N}^{*}$ if and only if $K>\frac{\left(\sqrt{2 \gamma+\alpha \sigma_{S}^{2}}-\sqrt{2 \gamma}\right)^{2}\left(\theta-\mu_{S}\right)^{2}}{2 \alpha^{2} \sigma_{S}^{4}}$,

\footnotetext{
${ }^{41}$ This situation arises in area $A$ in Figure 6 such that $F \in\left(\mu_{S}, \bar{F}_{1}\right)$.
} 


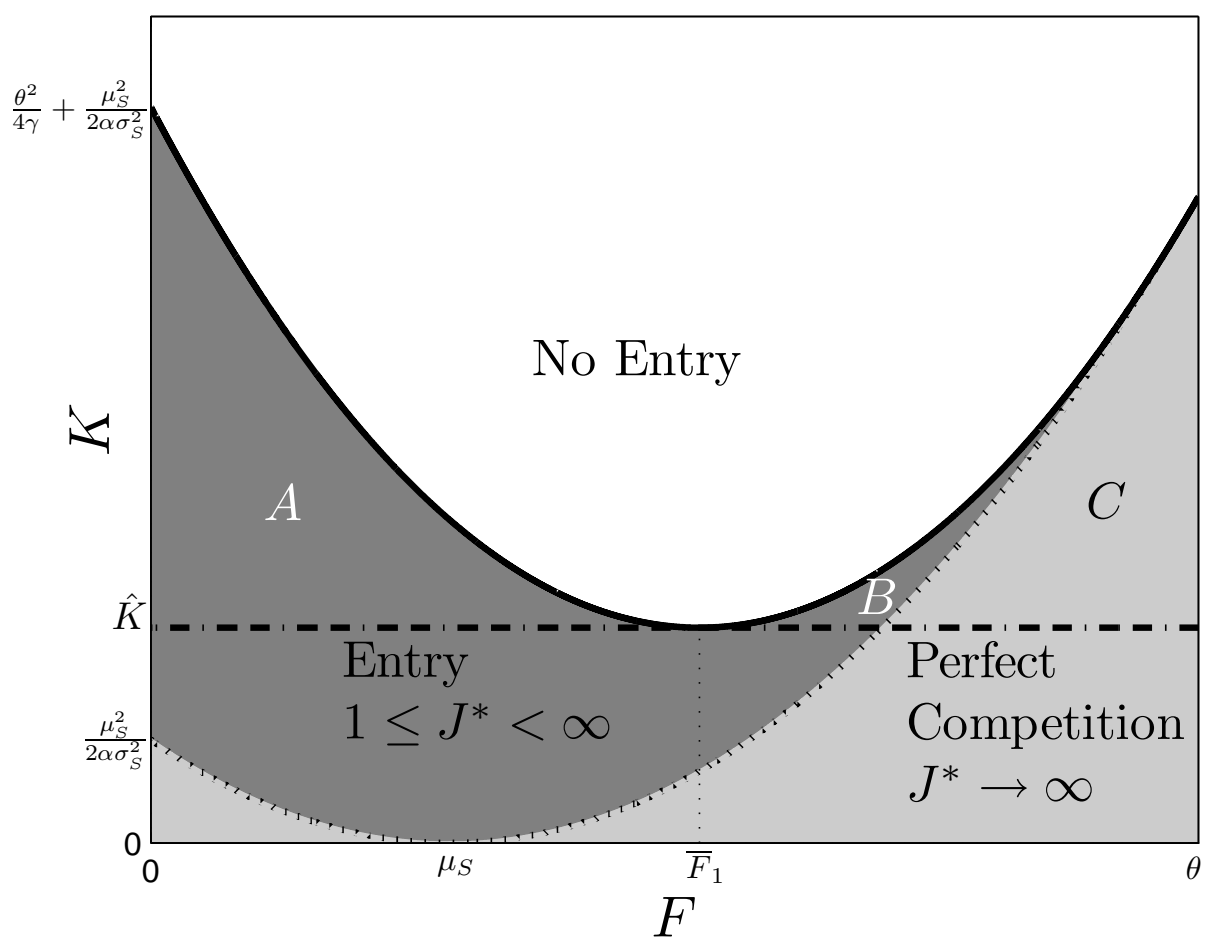

Figure 6: Entry, Access vs. No Access to the Futures Market

which is the same as the lower bound in (28). The inequality $\frac{\left(\theta-\mu_{S}\right)^{2}}{2\left(\sqrt{2 \gamma+\alpha \sigma_{S}^{2}}+\sqrt{2 \gamma}\right)^{2}}<$ $\frac{\left(\theta-\mu_{S}\right)^{2}}{2\left(2 \gamma+\alpha \sigma_{S}\right)}$ holds always.

To understand why access to the futures market may lead to a lower number of firms, we need to show how the ordering of (15) and (21) depends on the value of the futures price. To that end, we first illustrate the pattern graphically. We then study in details the effect of $F$ on $N^{*}$ and show that due to the convex shape of $N^{*}$ as a function of $F, N^{*}$ can be either below or above $\hat{N}^{*}$.

Consider Figure 7, where $F \in\left[\mu_{S}, \theta\right)$ is on the $x$-axis, while $N^{*}>0$ is on the $y$-axis. The convex solid line plots $N^{*}$ as a function of $F$, which is the general shape of (15). The straight dash-dot line is the number of firms under no access to the futures market. From (21), $\hat{N}^{*}$ is independent of $F$. 

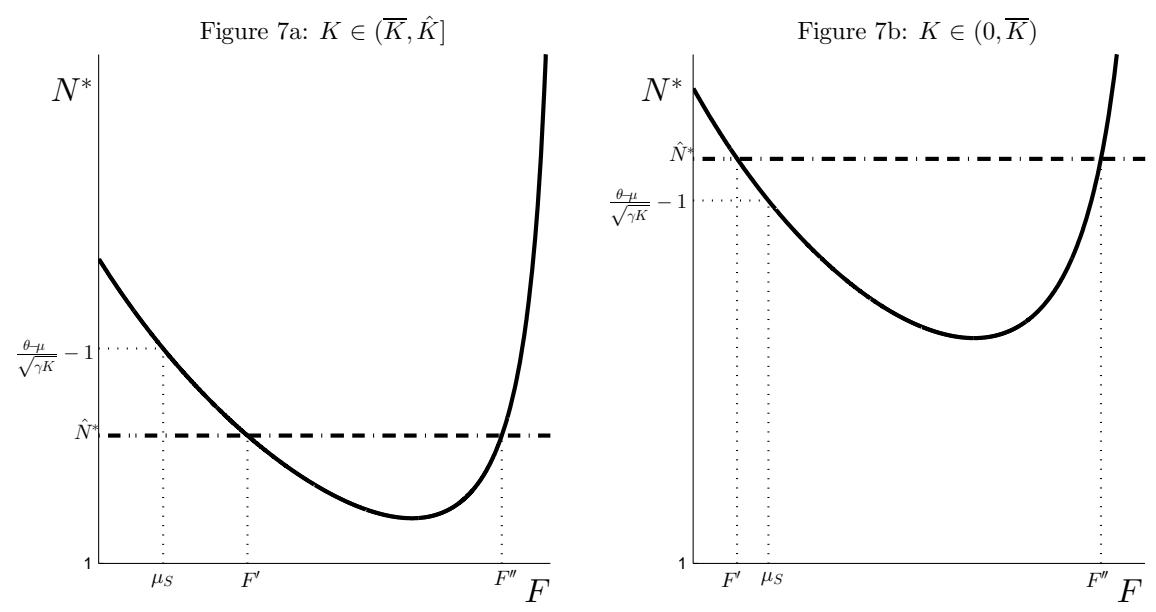

Figure 7: Number of Firms

When the convex curve intersects the straight line from below at $F=F^{\prime \prime}$ in Figure 7a, the firms switch from partial hedging to speculation, i.e., from $\omega^{*}\left(N^{*}\right) \in(0,1)$ to $\omega^{*}\left(N^{*}\right)<0 .{ }^{42}$

Consider first the case in which $\left.N^{*}\right|_{F=\mu_{S}}>\hat{N}^{*}$ as depicted in Figure 7a. Here, the entry cost is high in the sense that $K \in(\bar{K}, \hat{K}], \bar{K} \equiv$ $\frac{\left(\theta-\mu_{S}\right)^{2}}{2\left(\sqrt{2 \gamma+\alpha \sigma_{S}^{2}}+\sqrt{2 \gamma}\right)^{2}}$, as in (28). Note that, as long as the futures price is close enough to $\mu_{S}$, hedging yields more firms in the industry. Consider next the case in which $\left.N^{*}\right|_{F=\mu_{S}}<\hat{N}^{*}$ as depicted in Figure $7 \mathrm{~b}$. Here, the entry cost is low, i.e., $K \in(0, \bar{K})$. Regardless of the futures price, hedging always yields fewer firms in the industry. While access to the futures market may increase or decrease the number of firms when partial hedging occurs, ${ }^{43}$ it is clear from Figures $7 \mathrm{a}$ and $7 \mathrm{~b}$ that speculation in a contango situation always yields more firms. ${ }^{44}$

Having shown graphically that the ordering of $N^{*}$ and $\hat{N}^{*}$ depends on $F$, we now provide the derivative of $N^{*}$ with respect to $F$ in Proposition 4.10. Consistent with Figure 7, $N^{*}$ first decreases, then increases. We then explain

\footnotetext{
${ }^{42}$ Hence, $F^{\prime \prime}$ is the largest value of the futures price such that $N^{*}=\hat{N}^{*}$ and $\partial N^{*} / \partial F>$ 0 . From (18), $\left.\omega^{*}\left(N^{*}\right)\right|_{F=F^{\prime \prime}}=0$.

${ }^{43}$ Recall that $\omega^{*}\left(N^{*}\right) \in(0,1)$ when $F \in\left(\mu_{S}, F^{\prime \prime}\right)$.

${ }^{44}$ Recall that $\omega^{*}\left(N^{*}\right)<0$ when $F \in\left(F^{\prime \prime}, \theta\right)$.
} 
why an increase in $F$ can lead to a higher number of firms in the industry even when the firms partially hedge (for $F \in\left(\mu_{S}, F^{\prime \prime}\right)$ ).

Proposition 4.10. Suppose that firms have access to the futures market. Then,

1. For $F \in\left(0, \mu_{S}\right), \frac{\partial N^{*}}{\partial F}<0$.

2. For $F \in\left[\mu_{S}, \theta\right), \frac{\partial N^{*}}{\partial F}>0$ if and only if $F>\mu_{S}+\frac{2 \alpha \sigma_{S}^{2}}{\theta-\mu_{S}}$.

Proof. Differentiating (15) yields

$$
\frac{\partial N^{*}}{\partial F}=\frac{-\sqrt{\left(K-\frac{\left(F-\mu_{S}\right)^{2}}{2 \alpha \sigma_{S}^{2}}\right) \gamma}+\frac{\left(F-\mu_{S}\right)}{2 \alpha \sigma_{S}^{2}}(\theta-F)\left(K-\frac{\left(F-\mu_{S}\right)^{2}}{2 \alpha \sigma_{S}^{2}}\right)^{-\frac{1}{2}} \sqrt{\gamma}}{\left(K-\frac{\left(F-\mu_{S}\right)^{2}}{2 \alpha \sigma_{S}^{2}}\right) \gamma}
$$

which yields the cases stated in Proposition 4.10.

Before proceeding with a detailed explanation of this result, note that the positive relationship between the futures price and the number of firms entering the industry may occur not only when firms speculate, but also when firms partially hedge in a contango futures market. See conditions (20) and (22) in online Appendix 3. ${ }^{45}$ Note also that an increase in $F$ does not yield the same effect as a decrease in $\mu_{S}$. The reason is that, due to the separation result at stage 2 of the game, a change in $\mu_{S}$ alters stage2 certainty equivalent directly. However, a change in $F$ has both a direct effect and an indirect effect (through policy functions) on stage- 2 certainty equivalent.

${ }^{45}$ To obtain $\frac{\partial N^{*}}{\partial F}>0$ when the firms hedge, the following must hold

$$
\frac{\left(F-\mu_{S}\right)\left(\theta-\mu_{S}\right)}{2 \alpha \sigma_{S}^{2}}>\frac{\left(2 \gamma+\alpha \sigma_{S}^{2}\right)\left(F-\mu_{S}\right)^{2}}{2 \alpha^{2} \sigma_{S}^{4}} .
$$

Rearranging (30) yields

$$
F<\frac{2 \gamma \mu_{S}+\alpha \sigma_{S}^{2} \theta}{2 \gamma+\alpha \sigma_{S}^{2}} \equiv \bar{F}_{1},
$$

which, from Remark 4.3, is a necessary condition on the value of the futures price for hedging to occur. See also Figure 3. 
We now provide an explanation for the positive relationship between the futures price and the number of firms entering the industry. Due to strategic interactions, an increase in $F$ might increase stage-2 certainty equivalent for a given $N$, which enables more firms to cover the entry cost, and, thus, enter the industry. To show this, we study the effect of $F$ on the stage- 2 certainty equivalent for a given number of firms in the industry. Indeed, if $F$ increases $C E^{*}(N)$, then $N^{*}$ implicitly defined by $C E^{*}\left(N^{*}\right)=K$ increases as well. Using (26), $C E^{*}(N)$ is strictly increasing in $F$ if and only if

$$
\frac{(1+N)^{2} \gamma \mu_{S}+2 \alpha \sigma_{S}^{2} \theta}{(1+N)^{2} \gamma+2 \alpha \sigma_{S}^{2}}<F<\theta
$$

Hence, the firms might not necessarily benefit from a lower futures price due to a more competitive futures market. ${ }^{46}$ In other words, stage- 2 certainty equivalent is not necessarily decreasing in the futures price. In fact, $C E^{*}(N)$ is convex in $F$, so that a lower futures price may lead to a lower stage2 certainty equivalent. This effect occurs sometimes when firms partially hedge, and always when firms speculate. Further, it can only occur in a contango situation. In other words, $C E^{*}(N)$ is decreasing in $F$ under normal backwardation and actuarially fair pricing.

The positive relationship between stage- 2 certainty equivalent and $F$ when the firms partially hedge is due to the fact that an increase in the cost of hedging induces firms to decrease output, which can mitigate the effect of increasing output due to the strategic interaction of the firms. ${ }^{47}$ Specifically, the effect of an increase in the futures price on the stage- 2 certainty equivalent is two-fold. First, an increase in $F$ directly decreases stage-2 certainty equivalent. Second, there is an indirect effect through the behavior of the firms, i.e., an increase in $F$ induces firms to decrease production. This, in turn, mitigates the externality that the firms have on one another, which may increase stage-2 certainty equivalent. Both effects pull in opposite directions and the overall effect is ambiguous. See online Appendix 6 for a

\footnotetext{
${ }^{46} \mathrm{~A}$ more competitive futures market might arise in the presence of risk-neutral speculators.

${ }^{47}$ The firms partially hedge when $F$ is such that $\frac{(1+N)^{2} \gamma \mu_{S}+2 \alpha \sigma_{S}^{2} \theta}{(1+N)^{2} \gamma+2 \alpha \sigma_{S}^{2}}<F<\frac{(1+N) \gamma \mu_{S}+\alpha \sigma_{S}^{2} \theta}{(1+N) \gamma+\alpha \sigma_{S}^{2}}$.
} 

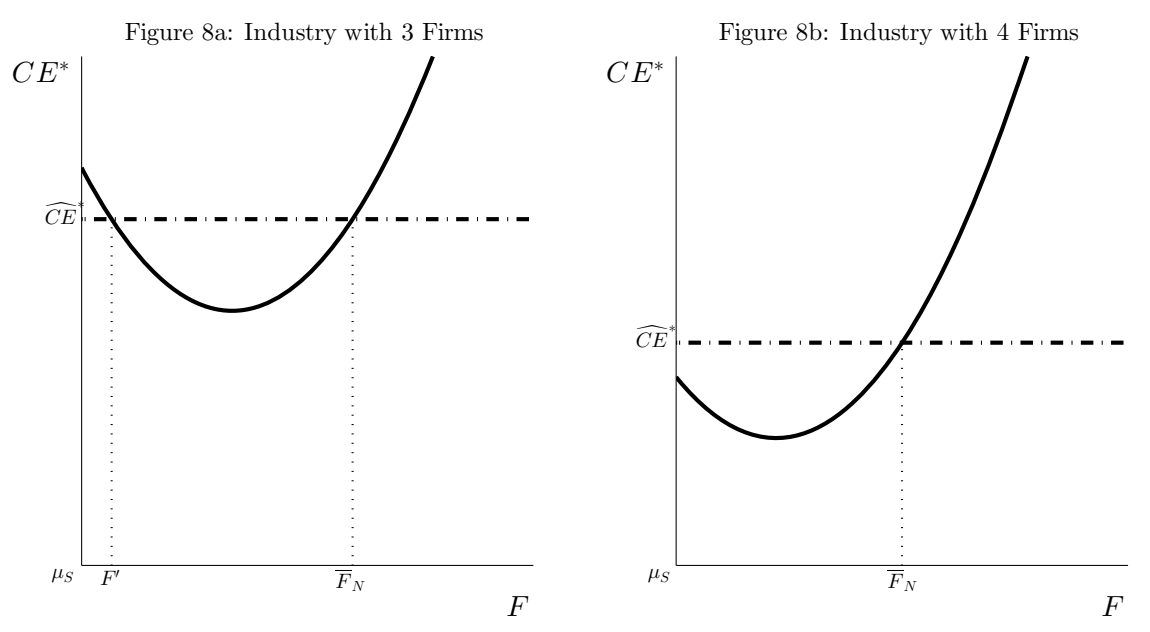

Figure 8: The Effect of $F$ on $C E^{*}(N)$

formal exposition.

Figure 8 depicts the effect of the futures price on the stage- 2 certainty equivalent resulting from the strategic interaction of the firms in a noncooperative game. Specifically, Figures $8 \mathrm{a}$ and $8 \mathrm{~b}$ depict the stage- 2 certainty equivalent of a firm with contango for an industry with $N=3$ firms and $N=4$ firms, respectively. ${ }^{48}$ For low futures prices, the firm hedges. For prices greater than $\bar{F}_{N} \equiv \frac{(1+N) \gamma \mu_{S}+\alpha \sigma_{S}^{2} \theta}{(1+N) \gamma+\alpha \sigma_{S}^{2}}$, the firm produces without hedging the random cost, but speculates.

For the case in which there is no speculation in equilibrium (i.e., $F \in$ $\left.\left[\mu_{S}, \bar{F}_{N}\right]\right)$, we make an additional comment. In Figure 8a, with $N=3$, each firm attains his highest stage-2 certainty equivalent when the price of hedge coverage is actuarially fair, $F=\mu_{S}$. Here, hedging results in higher stage-2 certainty equivalent as long as $\mu_{S} \leq F \leq F^{\prime}$. However, in Figure 8b, with $N=4,\left.C E^{*}\right|_{F=\mu_{S}}$ is not the highest value. The ambiguous effect of the cost of hedging on stage- 2 certainty equivalent implies that a more competitive futures market due in part to risk-neutral speculators might be detrimental to the firms.

\footnotetext{
${ }^{48}$ The values of the remaining parameters of the model are $\theta=10, \gamma=\mu_{S}=\sigma_{S}^{2}=\alpha=1$.
} 


\section{$5 \quad$ Final Remarks}

This paper provides an analysis of the firms' production and hedging decisions under imperfect competition with potential entry. Entry is shown to remove the separation result, i.e., although the firms have access to the futures market, their production decisions depend on uncertainty and risk aversion through the determination of the number of firms in the industry. We also show that the use of futures contracts have an ambiguous effect on the market structure of the industry. For instance, access to the futures market may increase or decrease the number of entering firms. For the effect of access to futures market, it is worth exploring in future whether our results hold in general.

To study the interaction between entry and the futures market, we have abstracted from three important aspects. First, we have assumed that the spot and futures prices were exogenous. However, these prices are determined by markets as well, which, in turn, affects resources allocation, production decisions, and risk-taking. Extending the model to include suppliers of the input along with speculators is an avenue for future research. While the determination of spot and futures prices has already been studied by Turnovsky (1983), the output producers are assumed to be passive, i.e., their demand for the input is given. In fact, output producers are active and forward-looking and, as shown in this paper, their output and input decisions are entwined. Second, we have ignored the role of financial decisions in deterring entry. It would also be interesting to study how strategic hedging from an incumbent firm may alter the decision entry of a potential entrant. For instance, Maskin (1999) considers a model in which capacity installation by an incumbent firm serves to deter others from entering the industry. Uncertainty about demand or costs forces the incumbent to choose a higher capacity level than it would under certainty. This higher requirement for capacity diminishes the attractiveness of deterrence. It would be interesting to study the incumbent's incentive to deter entry when it has access to futures markets.

Finally, an empirical extension would be to test the model in the airline industry or any industry with similar characteristics facing Cournot competi- 
tion. Recent empirical tests on hedging were limited to the effect of different determinants such as CEO risk aversion, convexity of tax function, corporate governance, distress costs, information asymmetry, and the effect of hedging on firm value. To our knowledge, no study has analyzed the effect of hedging on entry. The main empirical question would be: Do airline companies that hedge (or speculate) enter different routes more aggressively? Our theoretical results are ambiguous on this question and an empirical prediction from the model is that airline companies produces less in different routes when futures prices are high, which induces more firms to enter and hedge their fuel cost. 


\section{A Proofs}

Proof of Proposition 3.2. Letting $x_{j} \equiv\left(1-\omega_{j}\right) q_{j}$ be the units of output for which firm $j$ does not hedge and using (2), (5) is rewritten as

$$
\max _{q_{j}, x_{j}} \int_{0}^{P(0)} u\left(P\left(q_{j}+Q_{-j}^{*}\right) q_{j}-F q_{j}+(F-S) x_{j}\right) \cdot \phi(S) \mathrm{d} S
$$

where $Q_{-j}^{*} \equiv(J-1) q^{*}(J)$ is the total output of the other firms. Since the Hessian matrix is negative definite, ${ }^{49}$ firm $j$ 's best-response is defined by the first-order conditions

$$
\begin{aligned}
& q_{j}: \int_{0}^{P(0)}\left(P^{\prime}\left(q_{j}+Q_{-j}^{*}\right) q_{j}+P\left(q_{j}+Q_{-j}^{*}\right)-F\right) \\
& \quad \times u^{\prime}\left(P\left(q_{j}+Q_{-j}^{*}\right) q_{j}-F q_{j}+(F-S) x_{j}\right) \cdot \phi(S) \mathrm{d} S=0
\end{aligned}
$$

and

$$
x_{j}: \int_{0}^{P(0)}(F-S) \cdot u^{\prime}\left(P\left(q_{j}+Q_{-j}^{*}\right) q_{j}-F q_{j}+(F-S) x_{j}\right) \cdot \phi(S) \mathrm{d} S=0 .
$$

First, consider expression (34). Since $u^{\prime}>0$, it follows that

$$
\int_{0}^{P(0)} u^{\prime}\left(P\left(q_{j}+Q_{-j}^{*}\right) q_{j}-F q_{j}+(F-S) x_{j}\right) \cdot \phi(S) \mathrm{d} S>0 .
$$

Hence, (34) holds if and only if

$$
P^{\prime}\left(q_{j}+Q_{-j}^{*}\right) q_{j}+P\left(q_{j}+Q_{-j}^{*}\right)-F=0
$$

since (37) is not a function of $S$. From Assumption 2.2, firm $j$ 's best-response function to the output of the other firms has a nonpositive slope larger than

\footnotetext{
${ }^{49}$ See online Appendix 1.
} 
-1 , i.e., from $(37), \partial q_{j} / \partial Q_{-j}^{*} \in(-1,0)$. Hence, $q^{*}(J)$ is uniquely defined by (37) evaluated at $q_{j}=q^{*}(J)$, which yields (8). Second, consider expression (35). Since $u^{\prime \prime}<0$ and given that $q^{*}(J)$ exists and is unique, $x^{*}(J)$ exists and is unique. Since $x^{*}(J)=\left(1-\omega^{*}(J)\right) q^{*}(J)$, it follows that $\omega^{*}(J)$ exists and is uniquely defined by (9).

Proof of Proposition 3.4. We need to show that the left-hand side of (11) is strictly decreasing in $N$.

1. The term $P\left(N q^{*}(N)\right) q^{*}(N)-F q^{*}(N)$ in the left-hand side of (11) is strictly decreasing in $N$, i.e.,

$$
\frac{\partial\left(P\left(N q^{*}(N)\right) q^{*}(N)-F q^{*}(N)\right)}{\partial N}<0
$$

since, from (8), $\partial q^{*}(N) / \partial N<0$ and $\partial\left(N q^{*}(N)\right) / \partial N>0 .{ }^{50}$

2. Plugging $x^{*}(N) \equiv\left(1-\omega^{*}(N)\right) q^{*}(N)$ into the left-hand side of (11) and applying the envelope theorem, the derivative of the left-hand side

${ }^{50}$ Given Conditions 2 and 3 of Assumption 2.2 and $q^{*}(N)>0$, differentiating (8) yields

$$
\frac{\partial q^{*}(N)}{\partial N}=-\frac{P^{\prime \prime}\left(N q^{*}(N)\right) q^{*}(N)+P^{\prime}\left(N q^{*}(N)\right)}{P^{\prime \prime}\left(N q^{*}(N)\right) N q^{*}(N)+(N+1) P^{\prime}\left(N q^{*}(N)\right)} q^{*}(N)<0 .
$$

Hence,

$$
\frac{\partial\left(N q^{*}(N)\right)}{\partial N}=\frac{P^{\prime}\left(N q^{*}(N)\right)}{P^{\prime \prime}\left(N q^{*}(N)\right) J q^{*}(N)+(N+1) P^{\prime}\left(N q^{*}(N)\right)} q^{*}(N)>0
$$


of (11) with respect to $N$ is

$$
\begin{aligned}
& \frac{\partial \int_{0}^{P(0)} u\left(P\left(N q^{*}(N)\right) q^{*}(N)-F q^{*}(N)+(F-S) x^{*}(N)\right) \cdot \phi(S) \mathrm{d} S}{\partial N} \\
& =\frac{\partial x^{*}(N)}{\partial N} \underbrace{\int_{0}^{P(0)}(F-S) \cdot u^{\prime}\left(P\left(N q^{*}(N)\right) q^{*}(N)-F q^{*}(N)+(F-S) x^{*}(N)\right) \cdot \phi(S) \mathrm{d} S}_{=0 \text { from }(9)} \\
& +\int_{0}^{P(0)} \frac{\partial\left(P\left(N q^{*}(N)\right) q^{*}(N)-F q^{*}(N)\right)}{\partial N} \\
& \times u^{\prime}\left(P\left(N q^{*}(N)\right) q^{*}(N)-F q^{*}(N)+(F-S) x^{*}(N)\right) \cdot \phi(S) \mathrm{d} S .
\end{aligned}
$$

Using (38) and the fact that $u^{\prime}>0$ implies that (41) is strictly negative.

Since (10) holds, and given (41), it follows that the left-hand side of (11) crosses the $u(K)$-line from above only once. Hence, $N^{*}$ (as defined by $(11)$ ) is unique and so is $J^{*}=\left\lfloor N^{*}\right\rfloor$.

Proof of Proposition 3.5. Since $J^{*}=\left\lfloor N^{*}\right\rfloor$, we use (11) to derive the effect of an increase in $m$ and $r$ on $J^{*}$. The proof has two steps. First, we establish the sign of $x^{*}(N)$. Second, we show the effects of an increase in $m$ and an increase in $r$ on the left-hand side of (11), which depends on the sign of $x^{*}(N)$.

1. We first sign $x^{*}(N) \equiv\left(1-\omega^{*}(N)\right) q^{*}(N)$. Plugging $x^{*}(N) \equiv(1-$ $\left.\omega^{*}(N)\right) q^{*}(N)$ into expression (9) (evaluated at $J=N$ ) yields

$$
\operatorname{cov}\left[(F-\tilde{S}), u^{\prime}\left(\Pi^{*}+(F-\tilde{S}) x^{*}(N)\right)\right]+(F-\mathbb{E} \tilde{S}) \cdot \mathbb{E} u^{\prime}\left(\Pi^{*}+(F-\tilde{S}) x^{*}(N)\right)=0,
$$

where $\mathbb{E}$ and cov are, respectively, the expectation operator and the covariance operator. Here, $\Pi^{*} \equiv P\left(N q^{*}(N)\right) q^{*}(N)-F q^{*}(N)$, and $\mathbb{E} u^{\prime}\left(\Pi^{*}+(F-\tilde{S}) x^{*}(N)\right)>0$.

(a) Suppose first that $F=\mathbb{E} \tilde{S}$. Then, from (42), it must be that $x^{*}(N)=0$ so that $\operatorname{cov}\left[(F-\tilde{S}), u^{\prime}\left(\Pi^{*}+(F-\tilde{S}) x^{*}(N)\right)\right]=0$. 
(b) Suppose next that $F>\mathbb{E} \tilde{S}$. Then, from (42), it must be that $x^{*}(N)>0$ so that $\operatorname{cov}\left[(F-\tilde{S}), u^{\prime}\left(\Pi^{*}+(F-\tilde{S}) x^{*}(N)\right)\right]<0$.

(c) Suppose that $F<\mathbb{E} \tilde{S}$. Then, from (42), it must be that $x^{*}(N)<0$ so that $\operatorname{cov}\left[(F-\tilde{S}), u^{\prime}\left(\Pi^{*}+(F-\tilde{S}) x^{*}(N)\right)\right]>0$.

2. Next, plugging $x^{*}(N) \equiv\left(1-\omega^{*}(N)\right) q^{*}(N)$ and $\phi(S)=\psi(S ; m, r)$ into (11) yields

$$
\int_{0}^{P(0)} u\left(P\left(N q^{*}(N)\right) q^{*}(N)-F q^{*}(N)+(F-S) x^{*}(N)\right) \cdot \psi(S ; m, r) \mathrm{d} S=u(K)
$$

evaluated at $N=N^{*}$. Using the sign of $x^{*}(N)$, the proof consists in showing that an increase in $m$ or an increase in $r$ changes the left-hand side of (43) thereby changing $N^{*}$, which in turn changes $J^{*}=\left\lfloor N^{*}\right\rfloor$. To that end, let

$\Gamma \equiv \int_{0}^{P(0)} u\left(P\left(N q^{*}(N)\right) q^{*}(N)-F q^{*}(N)+(F-S) x^{*}(N)\right) \cdot \psi(S ; m, r) \mathrm{d} S$

be the left-hand side of (43). 
(a) Consider first an increase in $m$. From (44), ${ }^{51}$

$$
\begin{aligned}
\frac{\partial \Gamma}{\partial m}= & \frac{\partial q^{*}(N)}{\partial m}\left(P^{\prime}\left(N q^{*}(N)\right) N q^{*}(N)+P\left(N q^{*}(N)\right)-F\right) \\
& \times \int_{0}^{P(0)} u^{\prime}\left(P\left(N q^{*}(N)\right) q^{*}(N)-F q^{*}(N)+(F-S) x^{*}(N)\right) \cdot \psi(S ; m, r) \mathrm{d} S \\
& +\frac{\partial x^{*}(N)}{\partial m} \\
& \times \int_{0}^{P(0)}(F-S) u^{\prime}\left(P\left(N q^{*}(N)\right) q^{*}(N)-F q^{*}(N)+(F-S) x^{*}(N)\right) \cdot \psi(S ; m, r) \mathrm{d} S \\
& -\int_{0}^{P(0)} u\left(P\left(N q^{*}(N)\right) q^{*}(N)-F q^{*}(N)+(F-S) x^{*}(N)\right) \cdot \frac{\partial \psi(S ; m, r)}{\partial m} \mathrm{~d} S
\end{aligned}
$$

where $\frac{\partial q^{*}(N)}{\partial m}=0$ due to the separation property stated in Remark 3.3, and, from (9),

$$
\int_{0}^{P(0)}(F-S) \cdot u^{\prime}\left(P\left(N q^{*}(N)\right) q^{*}(N)-F q^{*}(N)+(F-S) x^{*}(N)\right) \cdot \psi(S ; m, r) \mathrm{d} S=0 .
$$

Hence, (45) simplifies to

$$
\frac{\partial \Gamma}{\partial m}=\int_{0}^{P(0)} u\left(P\left(N q^{*}(N)\right) q^{*}(N)-F q^{*}(N)+(F-S) x^{*}(N)\right) \cdot \frac{\partial \psi(S ; m, r)}{\partial m} \mathrm{~d} S .
$$

The sign of (47) is for the moment ambiguous because $\frac{\partial \psi(S ; m, r)}{\partial m}$ may be positive or negative depending on the value for $S$. Inte-

\footnotetext{
${ }^{51}$ Here, the notation $\frac{\partial \psi(S ; m, r)}{\partial m}$ refers to the difference between two p.d.f.'s, i.e., for $m_{1}>m_{2}, \psi\left(S ; m_{1}, r\right)-\psi\left(S ; m_{2}, r\right)$ as used in Laffont (1989).
} 
grating by parts (47) yields

$$
\begin{aligned}
\frac{\partial \Gamma}{\partial m}= & \left.u\left(P\left(N q^{*}(N)\right) q^{*}(N)-F q^{*}(N)+(F-S) x^{*}(N)\right) \frac{\partial \Psi(S ; m, r)}{\partial m}\right|_{0} ^{P(0)} \\
& +x^{*}(N) \int_{0}^{P(0)} u^{\prime}\left(P\left(N q^{*}(N)\right) q^{*}(N)-F q^{*}(N)+(F-S) x^{*}(N)\right) \frac{\partial \Psi(S ; m, r)}{\partial m} \mathrm{~d} S
\end{aligned}
$$

where $\Psi(S ; m, r)$ is the c.d.f of $\tilde{S}$ and $\frac{\partial \Psi(S ; m, r)}{\partial m}$ refers to the difference between two c.d.f.'s. Since $\Psi(0 ; m, r)=0$ and $\Psi(P(0) ; m, r)=$ 1 for all $m$, the first term in (48) is equal to zero. Moreover, using the definition of first-order stochastic dominance and the fact that an increase in $m$ induces an increase in the mean of $\tilde{S}$, it follows that $\frac{\partial \Psi(S ; m, r)}{\partial m}<0$.

i. Suppose first that $F=\mathbb{E} \tilde{S}$ so that $x^{*}(N)=0$. Then, from (48), $\partial \Gamma / \partial m=0$, Hence, from (11), $N^{*}$ and thus $J^{*}=\left\lfloor N^{*}\right\rfloor$ remain unchanged with a change in $m$.

ii. Suppose next that $F>\mathbb{E} \tilde{S}(F<\mathbb{E} \tilde{S})$ so that $x^{*}(N)>0$ $\left(x^{*}(N)<0\right)$. Then, from (48), $\partial \Gamma / \partial m<0(\partial \Gamma / \partial m>0)$. Hence, from (11), $N^{*}$ and thus $J^{*}=\left\lfloor N^{*}\right\rfloor$ are weakly decreasing (weakly increasing) along with an increase in $m$. 
(b) Consider next an increase in $r$. From (44),

$$
\begin{aligned}
\frac{\partial \Gamma}{\partial r}= & \frac{\partial q^{*}(N)}{\partial r}\left(P^{\prime}\left(N q^{*}(N)\right) N q^{*}(N)+P\left(N q^{*}(N)\right)-F\right) \\
& \times \int_{0(0)} u^{\prime}\left(P\left(N q^{*}(N)\right) q^{*}(N)-F q^{*}(N)+(F-S) x^{*}(N)\right) \cdot \psi(S ; m, r) \mathrm{d} S \\
& +\frac{\partial x^{*}(N)}{\partial r} \\
& \times \int_{0}^{P(0)}(F-S) u^{\prime}\left(P\left(N q^{*}(N)\right) q^{*}(N)-F q^{*}(N)+(F-S) x^{*}(N)\right) \cdot \psi(S ; m, r) \mathrm{d} S \\
& -\int_{0}^{P(0)} u\left(P\left(N q^{*}(N)\right) q^{*}(N)-F q^{*}(N)+(F-S) x^{*}(N)\right) \cdot \frac{\partial \psi(S ; m, r)}{\partial r} \mathrm{~d} S
\end{aligned}
$$

where $\frac{\partial q^{*}(N)}{\partial r}=0$ due to the separation property stated in Remark 3.3, and, from (9),

$$
\int_{0}^{P(0)}(F-S) \cdot u^{\prime}\left(P\left(N q^{*}(N)\right) q^{*}(N)-F q^{*}(N)+(F-S) x^{*}(N)\right) \cdot \psi(S ; m, r) \mathrm{d} S=0 .
$$

Hence, (49) simplifies to

$$
\frac{\partial \Gamma}{\partial r}=\int_{0}^{P(0)} u\left(P\left(N q^{*}(N)\right) q^{*}(N)-F q^{*}(N)+(F-S) x^{*}(N)\right) \cdot \frac{\partial \psi(S ; m, r)}{\partial r} \mathrm{~d} S .
$$

The sign of (51) is for the moment ambiguous because $\frac{\partial \psi(S ; m, r)}{\partial m}$ may be positive or negative depending on the value for $S$. Inte- 
grating by parts (51) yields

$$
\begin{aligned}
\frac{\partial \Gamma}{\partial r}= & \left.u\left(P\left(N q^{*}(N)\right) q^{*}(N)-F q^{*}(N)+(F-S) x^{*}(N)\right) \frac{\partial \Psi(S ; m, r)}{\partial r}\right|_{0} ^{P(0)} \\
& +x^{*}(N) \int_{0}^{P(0)} u^{\prime}\left(P\left(N q^{*}(N)\right) q^{*}(N)-F q^{*}(N)+(F-S) x^{*}(N)\right) \frac{\partial \Psi(S ; m, r)}{\partial r} \mathrm{~d} S .
\end{aligned}
$$

As in (48), the first term in (52) is equal to zero. We cannot sign directly (52) because, by the definition of a mean-preserving spread, $\frac{\partial \Psi(y ; m, r)}{\partial r}$ may be positive or negative depending on the value of $S$. Integrating by parts (52) yields

$$
\begin{aligned}
\frac{\partial \Gamma}{\partial r}= & x^{*}(N) \cdot u^{\prime}\left(P\left(N q^{*}(N)\right) q^{*}(N)-F q^{*}(N)+(F-S) x^{*}(N)\right) \\
& \times\left.\left(\int_{0}^{S} \frac{\partial \Psi(y ; m, r) \mathrm{d} y}{\partial r}\right)\right|_{0} ^{P(0)} \\
& +\left(x^{*}(N)\right)^{2} \cdot \int_{0}^{P(0)} u^{\prime \prime}\left(P\left(N q^{*}(N)\right) q^{*}(N)-F q^{*}(N)+(F-S) x^{*}(N)\right) \\
& \times\left(\int_{0}^{S} \frac{\partial \Psi(y ; m, r) \mathrm{d} y}{\partial r}\right) \mathrm{d} S
\end{aligned}
$$

Since $\Psi(0 ; m, r)=0$ and $\Psi(P(0) ; m, r)=1$ for all $r$, the first term in (53) is equal to zero. Moreover, using the definition of a mean-preserving spread and the fact that an increase in $r$ induces a mean-preserving increase in the risk of $\tilde{S}$, it follows that $\frac{\partial \Psi(S ; m, r)}{\partial r}>$ 0 for all $S<P(0) .{ }^{52}$ From (53), $\partial \Gamma / \partial r<0$ since $x^{*}(N) \neq 0$ (from $F \neq \mathbb{E} \tilde{S})$ and $u^{\prime \prime}<0$. Hence, from (11), $N^{*}$ and thus $J^{*}=\left\lfloor N^{*}\right\rfloor$ are weakly decreasing along with an increase in $r$.

Proof of Proposition 3.6. Plugging $x^{*}(N) \equiv\left(1-\omega^{*}(N)\right) q^{*}(N)$ and

\footnotetext{
${ }^{52}$ We recall the integral definition of a mean-preserving spread. Suppose that for $x \in$ $[a, b], G(x)$ is a mean-preserving spread of $H(x)$. Then, $\int_{a}^{b}(G(x)-H(x)) \mathrm{d} x=0$ to preserve the same mean between the two distributions and, for all $z \in[a, b), \int_{a}^{z}(G(x)-H(x)) \mathrm{d} x>0$ so that $G(x)$ has more weight in the tails than $H(x)$.
} 
$u(\pi)=v(\pi ; \rho)$ into $(11)$ yields
$\int_{0}^{P(0)} v\left(P\left(N q^{*}(N)\right) q^{*}(N)-F q^{*}(N)+(F-S) x^{*}(N) ; \rho\right) \cdot \phi(S) \mathrm{d} S=u(K)$

evaluated at $N=N^{*}$. Let

$$
\Gamma \equiv \int_{0}^{P(0)} v\left(P\left(N q^{*}(N)\right) q^{*}(N)-F q^{*}(N)+(F-S) x^{*}(N) ; \rho\right) \cdot \phi(S) \mathrm{d} S
$$

be the left-hand side of (54). From (55),

$$
\begin{aligned}
\frac{\partial \Gamma}{\partial \rho}= & \frac{\partial q^{*}(N)}{\partial \rho}\left(P^{\prime}\left(N q^{*}(N)\right) N q^{*}(N)+P\left(N q^{*}(N)\right)-F\right) \\
& \times \int_{0}^{P(0)} v_{1}\left(P\left(N q^{*}(N)\right) q^{*}(N)-F q^{*}(N)+(F-S) x^{*}(N) ; \rho\right) \cdot \phi(S) \mathrm{d} S \\
& +\frac{\partial x^{*}(N)}{\partial \rho} \int_{0}^{P(0)}(F-S) \cdot v_{1}\left(P\left(N q^{*}(N)\right) q^{*}(N)-F q^{*}(N)+(F-S) x^{*}(N) ; \rho\right) \cdot \phi(S) \mathrm{d} S \\
& +\int \frac{\partial v\left(P\left(N q^{*}(N)\right) q^{*}(N)-F q^{*}(N)+(F-S) x^{*}(N) ; \rho\right)}{\partial \rho} \cdot \phi(S) \mathrm{d} S
\end{aligned}
$$

where $\frac{\partial q^{*}(N)}{\partial \rho}=0$ due to the separation property stated in Remark 3.3, and, from (9),

$\int_{0}^{P(0)}(F-S) \cdot v_{1}\left(P\left(N q^{*}(N)\right) q^{*}(N)-F q^{*}(N)+(F-S) x^{*}(N) ; \rho\right) \cdot \phi(S) \mathrm{d} S=0$.

Hence, (45) simplifies to

$$
\frac{\partial \Gamma}{\partial \rho}=\int \frac{\partial v\left(P\left(N q^{*}(N)\right) q^{*}(N)-F q^{*}(N)+(F-S) x^{*}(N) ; \rho\right)}{\partial \rho} \cdot \phi(S) \mathrm{d} S .
$$


Since an increase in $\rho$ means an increase in risk aversion, it follows that for $F \neq \mathbb{E} \tilde{S},(58)$ is negative for all $N^{53}$ Hence, from (11), $N^{*}$ and thus $J^{*}=\left\lfloor N^{*}\right\rfloor$ are weakly decreasing in $\rho$ because a more risk-averse firm requires a higher risk premium to remain in the market.

\footnotetext{
${ }^{53}$ Since $x^{*}(N) \neq 0$ when $F \neq \mathbb{E} \tilde{S}$, it follows that $v$ is strictly concave in $S$. Hence, for any $\rho_{1}, \rho_{2}: \rho_{2}>\rho_{1}$ and as long as $x^{*}(N) \neq 0$,

$$
\begin{aligned}
& \int v\left(P\left(N q^{*}(N)\right) q^{*}(N)-F q^{*}(N)+(F-S) x^{*}(N) ; \rho_{2}\right) \cdot \phi(S) \mathrm{d} S \\
& <\int v\left(P\left(N q^{*}(N)\right) q^{*}(N)-F q^{*}(N)+(F-S) x^{*}(N) ; \rho_{1}\right) \cdot \phi(S) \mathrm{d} S
\end{aligned}
$$




\section{References}

M. Alghalith. Hedging and Production Decisions under Uncertainty: A Survey. Cornell University Library, http://arxiv.org/abs/0810.0917, 2008.

B. Allaz and J.L. Villa. Cournot Competition, Forwards Markets and Efficiency. J. Econ. Theory, 59(1):1-16, 1993.

R.W. Anderson and J-.P. Danthine. Cross Hedging. J. Polit. Economy, 89 (6):1182-1196, 1981.

R.W. Anderson and J-.P. Danthine. Hedger Diversity in Futures Markets. Econ. J., 93(37):370-389, 1983.

R.N. Batra and A. Ullah. Competitive Firm and the Theory of Input Demand under Price Uncertainty. J. Polit. Economy, 28(3):537-548, 1974.

J.A. Brander and A. Zhang. Market Conduct in the Airline Industry: An Empirical Investigation. RAND J. Econ., 21(4):567-583, 1990.

M. Campello, Y. Lin, C. Ma, and H. Zou. The Real and Financial Implications of Corporate Hedging. J. Finance, 66(5):1615-1647, 2011.

J-.P. Danthine. Information, Futures Prices, and Stabilizing Speculation. $J$. Econ. Theory, 17(1):79-98, 1973.

P.M. DeMarzo and D. Duffie. Corporate Financial Hedging with Proprietary Information. J. Econ. Theory, 53(2):261-286, 1991.

P.A. Diamond and J.E. Stiglitz. Increases in Risk and in Risk Aversion. J. Econ. Theory, 8(3):337-360, 1974.

G. Dionne and M. Santugini. Online Appendix: Entry, Imperfect Competition, and Futures Market for the Input. Available at SSRN: http://ssrn.com/abstract=2450698, 2014.

G. Dionne and T. Triki. On Risk Management Determinants: What Really Matters? Europ. J. Finance, 19(2):145-164, 2013. 
R. Eldor and I. Zilcha. Oligopoly, Uncertain Demand, and Forward Markets. J. Econ. Bus., 42(1):17-26, 1990.

W. J. Ethier. International Trade and the Forward Exchange Market. Amer. Econ. Rev., 63(3):494-503, 1973.

G. Feder, R.E. Just, and A. Schmitz. Futures Markets and the Theory of the Firm under Price Uncertainty. Quart. J. Econ., 94(2):317-328, 1980.

T. Fisher and D.R. Kamerschen. Measuring Competition in the U.S. Airline Industry Using the Rosse-Panzar Test and Cross-sectional Regression Analyses. J. Appl. Econ., 6(1):73-93, 2003.

X. Freixas and J.-J. Rochet. Microeconomics of Banking. MIT press, 2008.

K.A. Froot and J. Stein. Risk Management, Capital Budgeting and Capital Structure Policy for Financial Institutions: An Integrated Approach. J. Finan. Econ., 47(1):55-82, 1998.

K.A. Froot, D. Scharfstein, and J. Stein. Risk Management: Coordinating Corporate Investment and Financing Policies. J. Finance, 48(5):16291658, 1993.

J.R. Graham and D.A. Rogers. Do Firms Hedge in Response to Tax Incentives? J. Finance, 57(2):815-839, 2002.

J.R. Graham and C. Smith. Tax Incentives to Hedge. J. Finance, 54(6): 2241-2263, 1999.

D.M. Holthausen. Hedging and the Competitive Firm under Price Uncertainty. Amer. Econ. Rev., 69(5):989-995, 1979.

R.E. Hoyt and A.P. Liebenberg. The Value of Enterprise Risk Management. J. Risk Ins., 78(4):795-822, 2011.

E. Katz and J. Paroush. The Effect of Forward Markets on Exporting Firms. Econ. Letters, 4(3):271-274, 1979. 
J.-J. Laffont. The Economics of Uncertainty and Information. MIT press, 1989.

T.-O. Léautier and J.-C. Rochet. On the Strategic Value of Risk Management. IDEI Working Paper 739, 2012.

H.E. Leland. Theory of the Firm Facing Uncertain Demand. Amer. Econ. Rev., 62(3):278-291, 1972.

E.S. Maskin. Uncertainty and Entry Deterrence. Econ. Theory, 14(2):429437, 1999.

P. Morrell and W. Swan. Airline Jet Fuel Hedging: Theory and Practice. Transport Reviews, 26(6):713-730, 2006.

J. Paroush and A. Wolf. The Derived Demand with Hedging Cost Uncertainty in the Futures Markets. Econ. J., 102(413):831-844, 1992.

J.-C. Rochet and S. Villeneuve. Liquidity Management and Corporate Demand for Hedging and Insurance. J. Financ. Interm., 20(3):303-323, 2011.

M. Rothschild and J.E. Stiglitz. Increasing Risk I. A Definition. J. Econ. Theory, 2(3):225-243, 1971.

A. Sandmo. On the Theory of the Competitive Firm under Price Uncertainty. Amer. Econ. Rev., 61(1):65-73, 1971.

J.A.C. Santos and K. Tsatsarinis. The Cost to Entry: Evidence from the Market for Corporate Euro Bond Underwriting. BIS working paper, 2003.

C. Smith and R. Stulz. The Determinants of Firm Hedging Policies. $J$. Finan. Quant. Anal., 20(4):391-405, 1985.

R.M. Stulz. Managerial Discretion and Optimal Financing Policies. J. Finan. Econ., 26(1):3-27, 1990.

R.M. Stulz. Rethinking Risk Management. J. Appl. Corp. Finance, 9(3): 8-25, 1996. 
P. Tufano. Who Manages Risk? An Empirical Examination of Risk Management Practices in the Gold Mining Industry. J. Finance, 51(4):1097-1137, 1996.

S.J. Turnovsky. The Determination of Spot and Futures Prices with Storable Commodities. Econometrica, 51(5):1363-1387, 1983.

J.-M. Viaene and I. Zilcha. The Behavior of Competitive Exporting Firms under Multiple Uncertainty. Int. Econ. Rev., 39(3):591-609, 1998. 